\title{
ॠUSGS

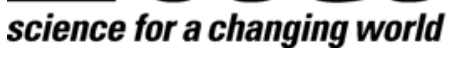

\section{Circulation and Physical Processes within the San Gabriel River Estuary During Summer 2005}

Kurt J. Rosenberger, Jingping Xu, Eric D. Stein, Marlene A. Noble, and Anne L. Gartner

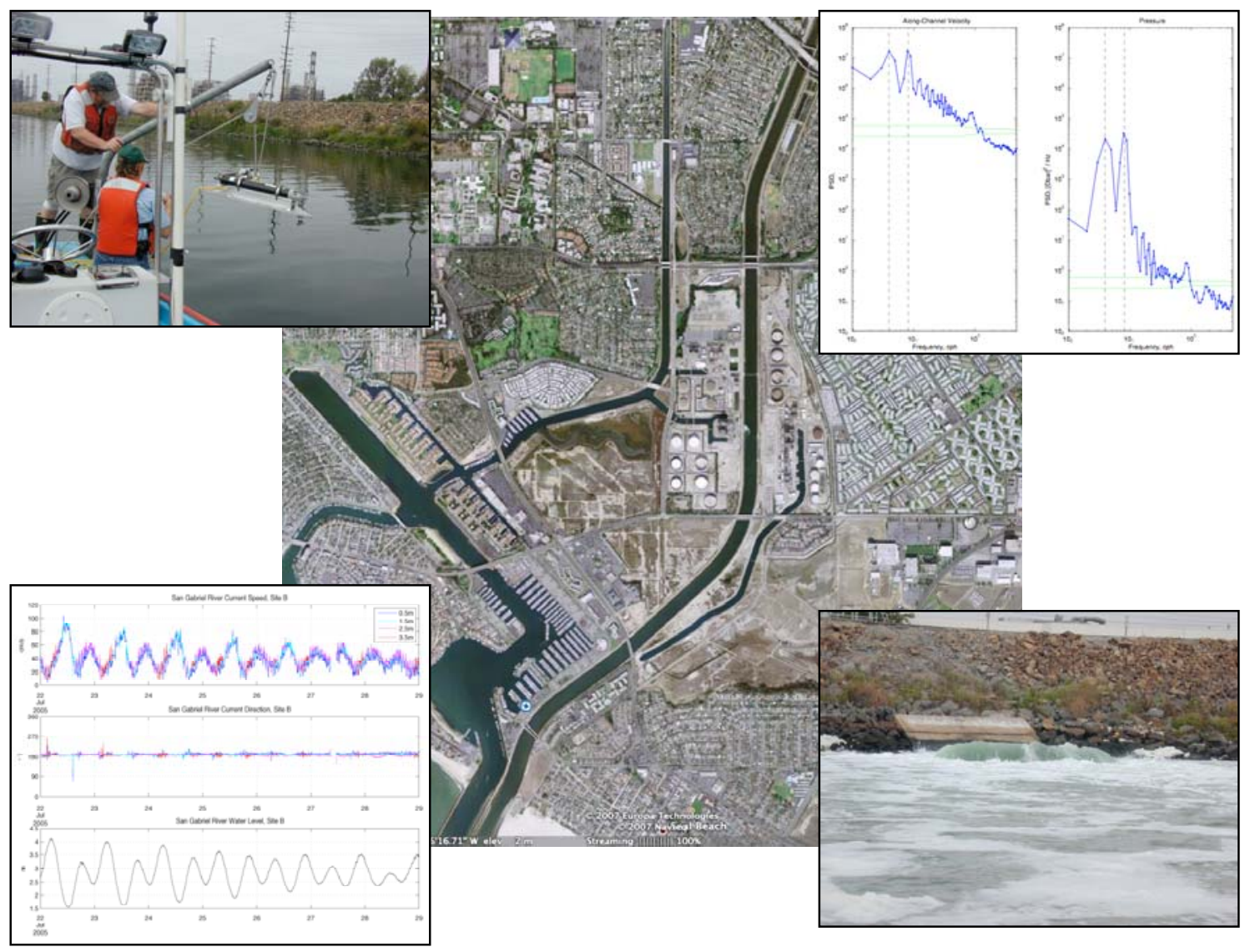

Open-File Report 2007-1011

U.S. Department of the Interior

U.S. Geological Survey 


\title{
U.S. Department of the Interior \\ DIRK KEMPTHORNE, Secretary
}

\author{
U.S. Geological Survey \\ Mark D. Myers, Director
}

U.S. Geological Survey, Reston, Virginia 2007

Revised and reprinted: 2007

For product and ordering information:

World Wide Web: http://www.usgs.gov/pubprod

Telephone: 1-888-ASK-USGS

For more information on the USGS - the Federal source for science about the Earth, its natural and living resources, natural hazards, and the environment:

World Wide Web: http://www.usgs.gov

Telephone: 1-888-ASK-USGS

Suggested citation:

Rosenberger, K, and others, 2007, Circulation and physical processes within the San Gabriel River estuary during summer 2005: U.S. Geological Survey Open-File

Report 2007-1011.

Any use of trade, product, or firm names is for descriptive purposes only and does not imply endorsement by the U.S. Government.

Although this report is in the public domain, permission must be secured from the individual copyright owners to reproduce any copyrighted material contained within this report. 


\section{Table of Contents}

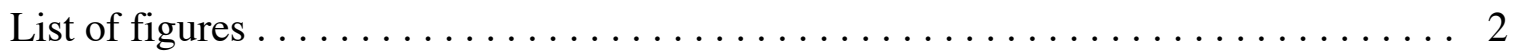

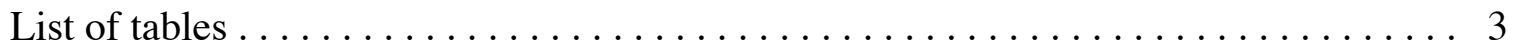

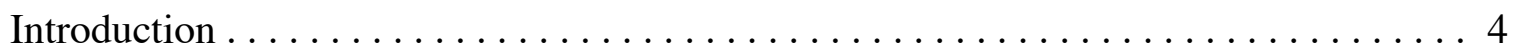

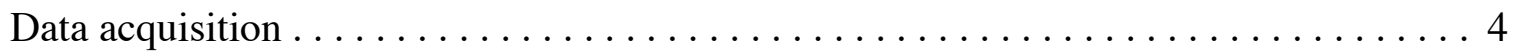

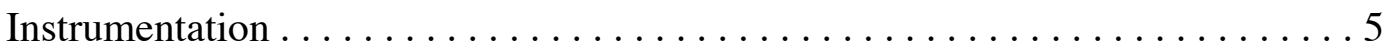

Surveys and instrument deployment $\ldots \ldots \ldots \ldots \ldots \ldots \ldots \ldots \ldots \ldots \ldots \ldots \ldots \ldots$

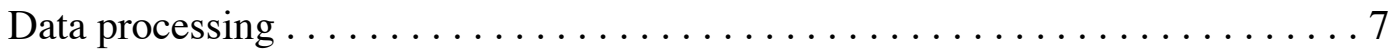

Instrument issues and additional processing $\ldots \ldots \ldots \ldots \ldots$

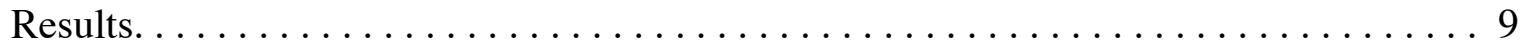

Estuary bed characterization $\ldots \ldots \ldots \ldots \ldots \ldots \ldots \ldots$

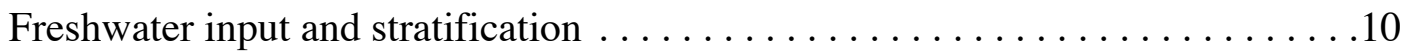

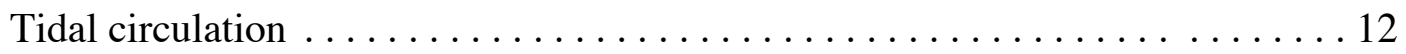

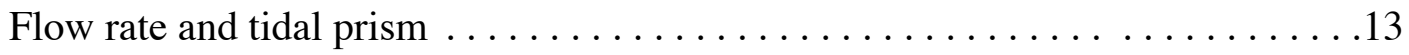

Summary. . . . . . . . . . . . . . .

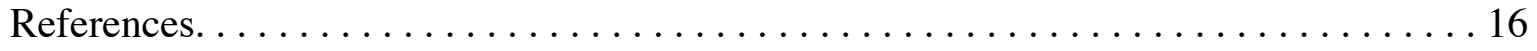

Figures

Tables

Appendices A-D 


\section{List of Figures}

Figure 1. Overview map of study area with position of San Gabriel River within the Southern California Bight.

Figure 2. Digital orthophoto of San Gabriel River estuary.

Figure 3. Photo of deployment of bottom platform for RD Instruments current meter at Site B.

Figure 4. Photo of bottom platform for Nortek Aquadopp current meter.

Figure 5. Photo of deployment of surface mooring with Microcat.

Figure 6. Photo of bottom platform for Seabird Microcat at Site A.

Figure 7. Map of locations of CTD casts taken during scoping survey on 17 May 2005.

Figure 8. Map of final deployment locations of all moored platforms.

Figure 9. Map of locations of CTD casts taken during deployment on 6 July 2005.

Figure 10. Map of locations of CTD casts taken during turnaround survey on 1 September 2005.

Figure 11. Map of locations of CTD casts taken during recovery on 13 October 2005.

Figure 12. Still-frame examples from video camera sled survey on 17 May 2005.

Figure 13. Time series of San Gabriel River discharge from Whittier Dam stream gauge and from combined flow measured at the lower San Gabriel River, Coyote Creek, and LACSD Long Beach Treatment Plant.

Figure 14. Sea-level pressure record from Site B, with sea level during periods of no data collection overplotted.

Figure 15. One-week time series of current speed and direction with depth at Site B, highlighting gaps in data record .

Figure 16. Time series of temperature, salinity, and density at Site A as recorded by moored Microcat $\mathrm{T} / \mathrm{S}$ sensors.

Figure 17. Time series of temperature, salinity, and density at Site B as recorded by moored Microcat $\mathrm{T} / \mathrm{S}$ sensors.

Figure 18. Time series of temperature, salinity, and density at Site $\mathrm{C}$ as recorded by moored Microcat $\mathrm{T} / \mathrm{S}$ sensors.

Figure 19. Low-pass-filtered time series of temperature, salinity, and density at Site C, surface (red) and bottom (blue).

Figure 20. Variance-preserving power spectra of bottom temperature recorded by Microcat at each site.

Figure 21. Variance-preserving power spectra of bottom salinity recorded by Microcat at each site.

Figure 22. Time series of current speed, direction, and water level at several depths as recorded by ADCP at Site B.

Figure 23. Time series of current speed, direction and water level at several depths as recorded by ADCP at Site B, for one week of deployment.

Figure 24. Variance-preserving power spectra of north-south velocity at Site B.

Figure 25. Time series of current speed, direction and water level at several depths as recorded by Nortek Aquadopp at Site C.

Figure 26. Time series of current speed, direction. and water level at several depths as recorded by Nortek Aquadopp at Site $\mathrm{C}$ for one week of deployment.

Figure 27. Log-Log plot of power spectra of water-level data at Site C.

Figure 28. Estimate of flow rate in the San Gabriel River estuary derived from hourly ADCP measurements at Site B and a 48-hour median filter of the estimated flow rate. 


\section{List of Tables}

Table 1. List of instruments deployed, parameters measured, and deployment locations and dates. Table 2. List of data acquired and data file names. 


\section{Introduction}

The San Gabriel River (SGR) is one of many rivers in the coastal lowlands of southern California that has been extensively modified in an effort to control flooding during the winter season. The river flows from the San Bernardino Mountains, north of Los Angeles, southward toward San Pedro Bay, and empties into the bay just east of the Ports of Los Angeles/Long Beach (Figure 1). Most of the river in the lowlands is lined with concrete, up to within $6.5 \mathrm{~km}$ from the coast. At this point the concrete river bed ends, and the tidally dominated river estuary begins. The river banks have been reinforced with rock rip-rap, and the river bed is mostly sandy bottom. This $6.5-\mathrm{km}$ stretch of the river leading to the ocean is commonly referred to as the SGR estuary. There are two natural-gas power-generating stations (PGS), one on either side of the river, with several units each. The plants require cooling water, for which the plant on the west side draws seawater from nearby Alamitos Bay, while the plant on the east draws from a channel leading to the ocean. This cooling water is subsequently discharged into the SGR at several points along the estuary at a slightly warmer temperature (Flow Science, 2005). There has been concern in the local community about water quality within the estuary, which has initiated studies on the causes of potentially degraded water quality.

The Southern California Coastal Water Research Project (SCCWRP) is developing a hydrodynamic model of the SGR estuary, which is part of the comprehensive water-quality model of the SGR estuary and watershed collaboratively investigated by SCCWRP and other local agencies. The hydrodynamic model will help understanding of 1) the exchange processes between the estuary and coastal ocean; 2) the circulation patterns in the estuary; 3 ) the residence time of water/particles in the estuary; and 4) impact of input from both the upstream natural runoff and the cooling discharge from PGS.

Like all models, the SGR hydrodynamic model is only useful after it is fully calibrated and validated. In May 2005, SCCWRP requested the assistance of the U.S. Geological Survey (USGS) Coastal and Marine Geology team (CMG) in collecting data on the hydrodynamic conditions in the estuary during the summer dry season. The summer was chosen for field data collection as this was assumed to be the season with the greatest potential for chronic degraded water quality due to low river flow and high thermal stratification within the estuary (due to both higher average air temperature and PGS output). Water quality can be degraded in winter as well, when high river discharge events bring large volumes of water from the Los Angeles basin into the estuary. The objectives of this project were to 1) collect hydrodynamic data along the SGR estuary; 2) study exchange processes within the estuary through analysis of the hydrodynamic data; and 3) provide field data for model calibration and validation. As the data only exist for the summer season, the results herein only apply to summer conditions.

\section{Data Acquisition}

Two primary data types were determined to be necessary for understanding the estuary dynamics: 1) temperature and salinity (T/S) data to understand thermohaline stratification; and 2) water-velocity data to gain a better understanding of the relative contributions of tidal exchange, riverine input, and PGS discharge to exchange processes and residence time in the estuary.

Time series of these data types were obtained at three moored locations within the estuary for approximately three months (Figure 2). Each site consisted of a bottom platform and a 
separate surface mooring anchored $\sim 50 \mathrm{~m}$ downstream for the placement of instrumentation. An internally recording $\mathrm{T} / \mathrm{S}$ sensor was placed on each bottom platform and surface mooring $(1 \mathrm{~m}$ below the water surface) to obtain data on changes in the vertical stratification in the water column through time. In addition, data on water currents were collected at two of the sites (Sites $\mathrm{B}$ and $\mathrm{C}$ ) by placing on the bottom platform an upward-facing acoustic Doppler current profiler (ADCP) that generates profiles of currents throughout the water column.

The two sites with profiling current meters were placed upstream and downstream of the PGS discharges in an effort to understand the effects of the thermal discharges on circulation within the estuary. The third site (Site A) with surface and bottom T/S only was placed near the estuary mouth to differentiate ocean-water masses from that of the river and discharges.

In addition to the time-series data, four surveys of vertical casts of conductivity (salinity), temperature, and depth (CTD) at several stations along the length of the estuary were conducted over the course of the moored deployment (Appendices A-D). The vessel R/V Panga of MBC Environmental was used for all field operations.

\section{Instrumentation}

Two types of profiling current meter and one type of T/S sensor were utilized for the moored equipment. Details on the instruments and the deployment setups are provided in this section.

\section{Acoustic Doppler current profilers (ADCP)}

ADCPs obtain a profile of water velocity by transmitting acoustic pulses into the water column and measuring the Doppler shift of the return pulse (scattered off particulate matter moving with the water) at multiple time lags, or distances from the transducer. The magnitude of the water velocity is then a function of the magnitude of the Doppler shift. The vertical range and resolution are a function of the frequency of the emitted pulse, the former being inversely proportional to frequency, and the latter being proportional. ADCPs can use either three or four acoustic beams to generate vertical profiles of the three-dimensional velocity (East, North, and vertical). The CMG group typically records velocity data in raw-beam coordinates, and appropriate transformations into East-North-Up Cartesian coordinates are done during postdeployment data processing. This allows for corrections to data that may be necessary due to improper instrument deployment, internal compass problems, or other such complications.

One RD Instruments Workhorse 1200-kHz ADCP was deployed on the bottom platform at Site B, oriented such that the beams were upward looking to obtain current profiles for the entire water column (Figure 3 ). The transducer head was approximately 0.15 meters above bottom (MAB), and a higher order sampling scheme was employed to generate high-resolution profiles consisting of 75 vertical bins $5 \mathrm{~cm}$ in length, ranging from 0.3 to $4 \mathrm{MAB}$. The instrument was set to collect 50 individual water pings to generate an average velocity every 6 minutes. In this higher order mode, the theoretical velocity resolution is $0.14 \mathrm{~cm} / \mathrm{s}$.

A 2-MHz Nortek Aquadopp profiler was deployed on the bottom platform at Site C, also oriented facing upward (Figure 4). This instrument provided current measurements in 25 vertical bins $10 \mathrm{~cm}$ in length, ranging from 0.24 to $2.64 \mathrm{MAB}$, every 12 minutes. As this instrument did not have as large a battery capacity, it could not collect profiles of currents as often as the RD 
Instruments ADCP. The theoretical horizontal velocity precision for this instrument was 2.3 $\mathrm{cm} / \mathrm{s}$.

\section{Conductivity-temperature $(\mathrm{CT})$ recorders}

CT recorders measure water temperature and conductivity at the sensor location and record the values at specified intervals. From these measurements, salinity can be calculated using an empirical formula.

For this program, the Seabird Electronics, Inc. SBE-37 MicroCats were used on each surface buoy and bottom platform to monitor changes in temperature and salinity. One MicroCat was placed on the vertical wire of the surface marker float, approximately $1 \mathrm{~m}$ below the surface (Figure 5). On the bottom platforms with profiling current meters, the MicroCats were placed horizontally so as not to interfere with the acoustic beams of the ADCP, and were pumped so that the sampling volume was flushed upon each sample to ensure no accumulation of material in the sample. On the third bottom platform (Site A), the MicroCat was placed on a vertical I-beam extending from a bottom plate with the sample volume at approximately the same depth level as the other platforms (Figure 6). This instrument also recorded water level via pressure sensor. All MicroCats were set to sample once every minute.

\section{Surveys and instrument deployment}

An initial survey was conducted on 17 May 2005, prior to the deployment of instrumentation, to evaluate the site in terms of water depth, bottom type, and potential navigational or human risks to deployed equipment. Transects running up and downstream of the river estuary were made, as a camera sled was towed and sediment grabs were taken to characterize the bottom type and choose final instrument locations. In addition, 20 CTD casts were taken to characterize the water properties at proposed locations, starting at the mouth of the river, and extending northward of the I-405 bridge crossing (Figure 7; Appendices A-D).

The deployment of moored instrumentation occurred on the morning of 6 July 2005. Mooring locations were logged with a handheld Garmin model GPS map 76 global positioning system (GPS) logger equipped with wide-area augmentation system (WAAS) enhanced positioning (Table 1). The vessel was anchored above the proposed bottom platform location, and the bottom platform lowered into position. Mooring line was let out to allow the vessel to drift downstream with the prevailing current, and a recovery line attached to the bottom platform was stretched out on the seafloor as this was done. Finally, the surface mooring was deployed independent of the bottom platform on the downstream side of the bottom platform, such that if the surface mooring were to drift downstream (the most likely scenario), its anchor would not catch on the bottom platform and potentially damage instruments. As it turned out, the power plant discharges produced higher than anticipated currents in the river, and thus the anchors for the surface moorings were not sufficiently heavy to prevent the surface moorings that were deployed downstream of the AES discharges from drifting downstream. The final instrument deployment locations are plotted in Figure 8, along with the recovery positions of the two moored instruments that drifted. A CTD survey of 17 profiles was also performed at the time of deployment (Figure 9).

As mentioned above, two surface moorings drifted within 1.5 months of deployment, and thus another trip was necessary to redeploy these two surface moorings in their original 
positions. The opportunity was taken to swap out the T/S sensors on these two surface moorings in the event that biofouling was preventing accurate salinity measurements. One USGS employee traveled to the site on 1 September 2005 to recover the two moorings that had drifted. Additional weight and scope was added to the mooring, the T/S sensor replaced with a fresh calibrated sensor, and the mooring redeployed in its original position. In addition, the opportunity to collect another series of 18 CTD casts was taken, and the upstream mooring was checked and cleaned (Figure 10).

All of the instruments were recovered on 13 October 2005. No additional drift of the surface moorings occurred during the period since the redeployment. All instruments were in good condition upon recovery, and considerably less growth on the moorings was observed upon final recovery. A final CTD survey of six casts was performed, including the three mooring locations (Figure 11).

\section{Data Processing}

All instruments were downloaded at the site and checked for clock drift upon recovery. Preliminary checks on quality and completeness were made to ensure program objectives were met. Data were then brought back to the CMG office at Menlo Park, CA, for processing.

Each instrument deployed by the USGS is given a unique mooring identifier, which can then be traced to the particular project and deployment location and time. A mooring platform is given a 3-digit ID number, and a fourth digit specifies any subsequent instruments attached to the platform. This four-digit number is then used for file-name conventions, so there is a unique file identifier for every instrument deployed by CMG.

The USGS CMG group has a standard set of computer programs through which all oceanographic data are processed to ensure consistency and completeness in quality control across all CMG projects. These programs were originally written in Fortran, and have since been translated to the Matlab scientific data-processing package for consistency with the oceanographic community. Raw data are first translated from the individual instrument manufacturer's format into the Network Common Data Format (NetCDF). NetCDF was developed by the Unidata group at the University Corporation for Atmospheric Research (http://www.unidata.ucar.edu/software/netcdf) for storing data arrays associated with earthscience research. The advantage of the NetCDF format is that it is platform independent, and can thus be easily shared among researchers using various computing environments. In addition, the data file format allows for the inclusion of metadata concerning the origin, data quality, history, etc., of the data, so that researchers can make informed decisions on the use of the data.

Once all data are in NetCDF format, they can then be processed and manipulated using one set of processing routines for a given data type. Clock accuracy for all instruments is first checked by comparing the deployment and recovery times in the mooring log to the first and last obvious good data points. Current profile data collected by ADCPs are then run through the CMG ADCPtool, which takes the raw-beam coordinate data and transforms it into earth coordinates, corrects for magnetic variation, and ensures a consistent timebase. The instrument also records data on the magnitude of the return pulse, correlation of the return pulse to the outgoing pulse, and an estimate of the percentage of good pings. CMG has established thresholds for these parameters for QA/QC purposes, which are based on over a decade of experience with ADCP data. Automatic data flagging using these thresholds is performed by ADCPtool, and the 
user is given the opportunity to further flag bad data points manually based on user knowledge of the system (such as the presence of schools of fish).

Since water level can vary with the tides, but the number (and size) of vertical bins of data acquired is typically fixed, there are often data points within the processed file that exist above the water surface, and are therefore nonsensical. These data points are typically retained, as there can be good data during periods of higher water level. However, in an environment where the tidal range is a significant portion of the water column (such as the SGR estuary), this can lead to confusion as to where the good data end. Thus, for this study, water-level data from instrument pressure sensors were used to determine the last good bin of data, and bins above this point were replaced with filler values. Problems with the higher order sampling scheme required a more detailed examination of the data to extract quality data from the data file, discussed below.

A similar process is employed for the T/S data, where the timebase is checked for consistency and raw conductivity is translated into salinity using an empirical formula (Fofonoff and Millard, 1983). Computed salinity data are then compared to other data sources (e.g., CTD profiles, river discharge data, historical data, etc.) to ensure that values are meaningful. Any obviously erroneous data points (such as a single data point several standard deviations above the mean) are removed and a fill value is placed.

After initial QA/QC checks, data are reviewed by a senior CMG oceanographer, and if no additional processing is deemed necessary, given the designation of Best Basic Version (BBV). As such, data are presented as the best quality possible with the least amount of processing performed, leaving gaps in the record where data were determined to be bad. In this manner, CMG allows collaborating researchers to decide for themselves if additional processing is necessary, and how or if gaps in the record are to be filled.

\section{Instrument issues and additional processing}

Each instrument recorded data as prescribed, and full data records were acquired, with the exception of two bottom MicroCats and the Nortek Aquadopp current meter, whose batteries were drained earlier than anticipated. In addition, there were difficulties with the RD Instruments shallow-water high-resolution sampling mode, described below. In the case of the MicroCats, the addition of a sample volume pump and a pressure sensor made the original battery calculations inaccurate. As for the Nortek, the instrument was returned to the manufacturer for testing, and no problem was found. Even though initial battery voltage was of the proper level, and a conservative battery drain calculation was used ( $80 \%$ drain), the instrument nonetheless stopped collecting early. The manufacturer maintains that their calculations were correct; however, it was noted that after this deployment, the manufacturer's claim of total battery capacity for this type of battery dropped $20 \%$.

An estimate of the total number of days of data collected by data type is listed in Table 2, along with file names of data files on the data $\mathrm{CD}$. Where two numbers exist in the column for the number of days of data, these refer to the two individual deployments (when surface moorings needed to be re-deployed).

The sampling arrangement utilized with the RD Instruments 1200-kHz ADCP (referred to by RD Instruments as 'Mode 11') employs a dual-ping scheme that allows for smaller vertical bins, and high-precision velocity estimates. However, if the in-situ flow is higher than the threshold for this sampling scheme ( $\sim 1 \mathrm{~m} / \mathrm{s}$ in $4 \mathrm{~m}$ water depth), it can lead to decorrelation 
between the two individual pings, which results in higher uncertainty in the velocity estimate. This can also occur if there is significant shear or turbulence in the water column, which was not expected in this application. This uncertainty is reflected in the 'Percent Good' estimate as recorded by the instrument. Using CMG thresholds for Percent Good and correlation approximately $27 \%$ of the entire record was salvageable, with the bulk of the bad data consisting of short gaps in time and depth. Again, CMG intentionally leaves gaps of bad data in the Best Basic Version; however, some of these gaps should be able to be interpolated linearly while maintaining fidelity to the dominant processes in the estuary (such as tides and PGS discharge). There was one large gap from 12 July to 20 July in which no good data were recoverable. It is possible that discharge was so high during this period that velocities were consistently above the threshold that would result in the aforementioned decorrelation. Without information on the volume of AES discharge or additional velocity data downstream of the discharge points, it is impossible to say from the data exactly why no data were recoverable from this period.

To determine if there was a particular pattern to periods of good or bad data, the water level and the points in the record when the data were considered bad (at 0.8 MAB) are plotted in Figure 12, in blue and red, respectively. Thus, the periods where good data were recovered show only blue. In general, periods of good data seem to occur preferentially at high or low tide, and typically not in between. In the absence of the artificial discharge in a channel with one open boundary to the ocean, one would expect peak velocities to occur during these periods of flooding or ebbing tide. It would therefore be possible that the data gaps are due to strong velocities above the threshold for the Mode 11 scheme. However, the presence of a consistent outgoing discharge means that incoming flood velocities should be reduced, and outgoing ebb velocities enhanced. Thus, if the data gaps were simply due to velocities within the estuary that were too high for the instrument to measure, we would only expect gaps on the ebb tide, which is not the case. Velocity data for a one-week period is plotted in Figure 13, showing that the instrument did record strong velocities on the ebb cycle. More importantly, however, there are periods of data gaps when we might expect velocities to be lower, such as on the flood tide, or occasionally on the slack tides. By this simple observation, it is reasonable to assume that the good data recovered by this instrument are not skewed towards a higher or lower velocity distribution.

\section{Results}

\section{Estuary bed characterization}

The initial survey to assess bottom type and water depths showed that in general, the bottom does not vary much in the SGR estuary. Water depth was relatively consistent, perhaps somewhat shallower in the upstream region. Bottom type was predominantly sandy, with a few $\mathrm{cm}$ of fine-grained organic material overlain on the surface in some locations, particularly upstream of the discharges. A couple of stations upstream of the discharges displayed an anaerobic sulfuric smell in the sediment grab sample. Examples from the video survey are shown in Figure 14. 


\section{Freshwater input and stratification}

Data on freshwater input to the river were collected from two sources. First, the daily average stream gauge record from the USGS Whittier Dam gauging station was downloaded (http://waterdata.usgs.gov/nwis - site 11087020) for comparison to the T/S and ADCP data. Secondly, data from two gauges on the lower SGR and Coyote Creek (which feeds into the SGR) maintained by the Los Angeles County Department of Public Works, as well as discharge data from the Los Angeles County Sanitation District (LACSD) Long Beach treatment plant were obtained by SCCWRP (Figure 15), heretofore referred to as the combined discharge. The SGR has been engineered such that water can be diverted to the Los Angeles River on an unscheduled basis if the need arises (either for flood control or water needs), and this diversion channel lies in between the SGR estuary and the Whittier Dam gauging station. Thus, as we have no way of determining when water is being diverted, the latter source for data on fresh water input to the system is more reliable.

Combined river discharge was fairly low for the measurement period, showing a few small peaks, and a slightly higher average flow during the second half of the deployment.

The discrepancy between the two stations is most likely due to the potential diversion of water from the SGR, as well as changes in the input from LACSD.

Variation in the degree of stratification over time was recorded by the surface and bottom $\mathrm{T} / \mathrm{S}$ sensors at each location. Plotted in Figures 16-18 are the salinity, temperature, and density (represented as Sigma-theta, or density in $\mathrm{kg} / \mathrm{m}^{3}$ minus $1000 \mathrm{~kg} / \mathrm{m}^{3}$ ) for Sites A, B, and C, respectively. Surface data are plotted in red and bottom data in blue. As the surface moorings moved during the course of deployment at Sites A and B, there are two data files for the surface instruments, with the first deployment plotted in red and the second in green.

Surface and bottom temperature and salinity at Site A were extremely similar over the entire deployment (Figure 16). Both temperature and salinity displayed tidal trends, but longterm average temperature varied more than salinity, alternating from $20^{\circ} \mathrm{C}$ to $30^{\circ} \mathrm{C}$ (with tidal peaks up to $34^{\circ} \mathrm{C}$ ), while average salinity hovered near $32 \mathrm{psu}$. There was one significant freshwater event on 20 September, in which salinity dropped to approximately $15 \mathrm{psu}$, which corresponds to a peak in river discharge as well. River discharge also showed a series of discharge peaks from late July to middle August; however, this was not reflected in the salinity data at this site. Temperature and salinity returned to levels observed prior to the freshwater event within a few tidal cycles.

Site B showed similar trends to Site A, with the exception of a gradual decrease in surface salinity (and hence, density) over the course of the first deployment (Figure 17). It is not uncommon for this to occur due to biofouling, which was noted when the instrument was exchanged on 1 September. This is due to the fact that the determination of salinity is based on the conductivity of a predefined volume of water, and as biota occupy the sample volume the conductivity is reduced. However, it is possible that the change noted was in part due to the relocation of the mooring. While we have no information as to exactly when the mooring moved, we can guess based on the data. For the first week and a half, the surface and bottom salinity tracked each other well at both Sites A and B. On approximately 14 July, the surface salinity at Site B began a gradual decline, but continued to increase and decrease in concert with bottom salinity on a semidiurnal frequency. On 12 August, the tidal oscillations ceased, and a consistent salinity with one short decrease was noted until 15 August, at which point the surface salinity 
varied in a manner opposite to that of the bottom, on what appeared to be a more diurnal frequency. It is believed that the mooring moved during this period between 12 and 15 August, and, having been relocated on a different side of the channel, was subsequently sampling a different water mass than in its previous location. This fact outlines the potential variability in circulation across estuary. Upon redeployment of the surface mooring, water-mass properties at the surface resumed tracking that of the bottom properties.

Aside from this data discrepancy, the T/S data at Site B followed very similar trends to Site A, if not nearly identical. One notable difference was a slight disparity between surface and bottom salinity during the period surrounding the discharge peak on 20 September in which surface salinity was 1-2 psu lower. This is the only period in which there appeared to be any stratification in the water column at this site.

Temperature and salinity data from Site $\mathrm{C}$, upstream of the discharges show somewhat different trends (Figure 18). Long-term subtidal trends are similar (such as the period of warmest temperature occurring in mid-July); however, tidal variability does not appear to be as significant, particularly in the bottom layers. In addition, average temperature and salinity is lower than the other two stations. There is also more difference between surface and bottom temperature and salinity at this site than the other two, which is not surprising given its proximity to the freshwater input of the river. Figure 19 shows the 33-hour low-pass filtered data from surface and bottom instruments at Site C. In this view, the disparity between surface and bottom water densities is more evident, averaging between $3-5 \mathrm{~kg} / \mathrm{m}^{3}$. It is also clear that on a few occasions, bottom waters were actually warmer than surface waters, which may correspond to periods when higher temperature discharge water from the PGS intruded upstream in the nearbottom layers. Since the salinity of the water is more important in the density, the bottom waters are still denser during these brief events.

Upon closer examination, the dominant oscillation period of temperature data is actually diurnal, whereas the period of the salinity data is semidiurnal, in both surface and bottom layers. Spectra of the hour-averaged bottom temperature and salinity data, plotted in Figures 20 and 21, respectively, confirm this observation. In particular, the diurnal signal is more prevalent in temperature at Sites A and B, and the semidiurnal signal is more prevalent in salinity at Sites A and $\mathrm{B}$, but not at Site $\mathrm{C}$. This discrepancy between temperature and salinity is most likely due to the fact that the PGS changes the temperature of the water, but not the salinity, as the cooling water originates from the ocean. Since electricity usage varies on a daily cycle, the volume and temperature of the discharge should vary diurnally as well. Daily solar heating and cooling may contribute to this signal as well, but alone could not account for the degree to which it varies nor the variation throughout the water column. Site $\mathrm{C}$, which is upstream of the discharges, shows a more diurnal signal in salinity, which may be due to excess treated wastewater discharge farther upstream into the SGR by the LACSD (pers. comm., Jon Warrick). The diurnal signal in temperature at Site $\mathrm{C}$ is most likely due to daily solar heating and cooling, as the water is quite shallow upstream of the estuary.

Raw data from CTD casts are plotted in Appendices A-D, but the general trend noted throughout the program was that the water column was stratified upstream of the discharges (up to $20 \mathrm{~kg} / \mathrm{m}^{3}$ difference), and vertically mixed downstream, with occasionally stratified water noted just downstream. Although the water column was vertically mixed downstream of the discharge, a slight decrease in density was noted towards the river mouth on 17 May, and a slight increase was noted on 1 September. A small cross-channel transect was made at the river mouth 
just downstream of the Marina Street bridge on 17 May, 6 July, and 1 September, and very little difference in water properties were noted across the river channel.

The fact that salinity varies on a semidiurnal cycle suggests that either a salinity front propagates up- and down-channel with the tide, or mixing of lower salinity river water with higher salinity ocean water occurs on a tidal basis. Data from CTD casts from both USGS and Flow Science only show a strong salinity front within the immediate vicinity of the discharges, and almost never downstream, regardless of tidal stage. Therefore the tidal variability in salinity is most likely due to tidal mixing of estuarine waters and incoming ocean waters.

\section{Tidal circulation}

Although there were instrument problems with the current meter downstream of the discharges, some data were recoverable. Plotted in Figure 22 are time series of current speed and direction for the entire deployment from four levels in the water column at Site B, just downstream of the discharges. These four levels correspond to $0.5,1.5,2.5$ and $3.5 \mathrm{~m}$ above the bottom. Small gaps in data are apparent as well as one large gap from 14 July to 21 July. The tidal nature of the currents is apparent in speed; however, direction is predominantly downstream throughout the water column, with the exception of a few periods of lower flow velocity. Assuming the ADCP data represent velocity across the channel, this suggests that the flow of PGS discharge downstream is stronger than incoming tidal water, and water level rises as discharge water pushes against the incoming tide. Plotted in Figure 23 is one week of data from the falling spring tide from data that have had small gaps linearly filled. There appear to be gaps in data as lines do not continue across the entire plot; however, this is due to the fact that the $\mathrm{ADCP}$ bin depths are fixed, and as the water level rises and falls, certain bin levels exist above the water surface at low tide.

Peak velocities throughout the water column occur at the end of the ebb, when the combined PGS discharge and tidal waters exit the estuary. Minimum velocities occur at slack high tide, when incoming tidal water balances outgoing discharge. Any current above zero at this point should therefore represent the velocity of the outgoing discharge. Since the entire water column appears to be flowing downstream at almost all times, but salinity at this site varies on a semi-diurnal basis, is further evidence of vigorous mixing between the estuary waters and incoming ocean water.

A higher frequency signal on top of the tidal signal is apparent in the data, which at first glance appears to be noise. However, spectra of the along-channel velocity and pressure confirm a peak in spectral energy between 1 and 1.5 hours (Figure 24). The two largest peaks are the semidiurnal and diurnal tide, and subsequent peaks higher in frequency show shallow water tidal harmonics $\left(\mathrm{M}_{4}, \mathrm{M}_{6}\right.$, etc.), and finally a peak at 1-2 hours. It is not clear what is causing a peak in energy at this frequency, whether it is the result of fluctuations in discharge, or a seiche within the estuary. A rough order-of-magnitude calculation of the fundamental (or uninodal) seiche period for an enclosed basin can be calculated using Merian's formula (Pond and Pickard, 1983):

$$
T=2 * L / \sqrt{ }(g * h)
$$

where $T$ is the seiche period, $L$ is the length of the basin, $g$ is the acceleration due to gravity, and $h$ is the mean water depth. Using a length of $6.5 \mathrm{~km}$ and mean water depth of $4 \mathrm{~m}$, we arrive at a seiche period of 2076 seconds, whereas a mean water depth of $1 \mathrm{~m}$ gives a seiche period of 4152 
seconds. Thus, depending on the stage of the tide, the seiche period of the estuary will fluctuate between 0.5 to 1.5 hours. The bandwidth of the observed spectral peak is fairly broad, indicating that the energy is not focused on one period, which corresponds with the notion that the seiche period of the estuary varies according to tidal stage. There must be forcing near this frequency for the estuary to resonate, and it is not clear what that forcing may be.

Site $\mathrm{C}$ showed considerably lower and more consistent flow magnitude than Site B; however, flow reversal upstream was more common at this location, particularly in the midwater column (Figure 25). This instrument was in slightly shallower water than Site B, but due to an underestimation of the tidal range before deployment, the full water column was not captured during higher-high tides. An expanded view of the data shows that the stronger velocities are typically at the surface on the outgoing tide, and that the velocity at this site exhibits the same higher frequency signal as at Site B (Figure 26). Surface waters typically show only downstream flow, while bottom or mid-depth flow can be upstream. Given that this site is upstream of the discharge, and the flow at the downstream location was predominantly out of the estuary, these waters most likely contain mostly discharge water, and not oceanic water. Since the discharge water is saltier than the river water, it will necessarily be denser (even though warmer) than the river water, so any upstream flow will be constrained to the bottom.

Another difference between Sites C and B is that the hourly signal not only exists in velocity magnitude, but also in direction at Site $\mathrm{C}$. This is most likely due to the fact that the strong discharge flow is not present at this location, and smaller amplitude higher frequency fluctuations have more influence on the overall circulation. The fact that the hourly fluctuations exist at this location upstream of the discharge suggest that it is, in fact, a seiche, and not a fluctuation in discharge. Spectra of the along-channel velocity and pressure (Figure 27) show the peak at this site as well. Since the peak exists in the velocity and pressure signal at both sites, this confirms that the seiche in velocity is due to a surface seiche, and not a fluctuation in discharge or an internal seiche due to density stratification.

Unfortunately, the current meter instrument batteries died at Site $\mathrm{C}$ before the freshwater event noted in the salinity data on 20 September, so we do not know how this influenced flow at this site.

\section{Flow rate and tidal prism}

Using the velocity and water-level data some first-order calculations on the flow rate within the estuary due to discharge and water level variation are possible. The typical channel cross-section from original construction had a bottom width of $73 \mathrm{~m}$ and a side slope of 27 degrees on each side, and the constructed estuary is $6.7 \mathrm{~km}$ (Flow Science, 2005). The tidal prism is defined as the difference between mean high water and mean low water. This was calculated using the pressure record by taking the Hilbert transform, which represents the amplitude of a waveform and doubling (to get the difference between high and low). This was determined to be $1.4 \mathrm{~m}$ for the SGR estuary. Thus, using the original construction geometry and a mean water depth of $2.7 \mathrm{~m}$ (the average of the mean at each site), the volume of the tidal prism is $785900 \mathrm{~m}^{3}$. Over the course of one-half tidal cycle (6.21 hours, from high to low), this corresponds to a flow rate of $35 \mathrm{~m}^{3} / \mathrm{s}$. This represents the average tidal flow into or out of the estuary from a mean high-water level to mean low-water level, or vice versa. 
We can also estimate the flow rate in the estuary using the velocity profile at the center of the channel. If we assume there is no cross-channel shear in velocity (that is, when the ADCP records flow exiting the estuary in the center, we assume it is not flowing into the estuary anywhere across-channel), an inverse power-law flow profile across channel (as in a pipe) can be used to estimate the flow at points where we don't have velocity data. First, a polynomial fit is applied to the velocity profile at the center of the channel to fill the profile should there be bad data points. Then the flow rate per unit $(1 \mathrm{~m})$ width for the center is calculated. Using a parabolic cross-channel velocity profile, the discharge at points $x$ across the channel is then calculated as

$$
U_{x}=(x-w)^{2} * U_{0} / w^{2}
$$

where $U_{0}$ is the velocity recorded at the center of the channel, and $w$ is half the channel width. Integrating this formula and doubling gives the total flow rate within the estuary. This was performed on the data from Site B, with small gaps being linearly interpolated. Results are plotted in Figure 28, with the raw discharge plotted in red, and a 48-hour median filter plotted in blue. In this formulation, positive flow rate corresponds to downstream flow (seaward). The black stars on the bottom axis indicate where there are still missing data points after interpolation. It is important to note that this calculation includes the flow of water exiting the estuary due to the combined discharge and tidal flow. As mentioned previously, the measured velocity at slack tide (both high and low) should be representative of the flow due to discharge alone, while at mid-tide cycle, this represents the combined discharge and tidal flow. Peak discharge is noted at the middle of the ebb cycle, and minimum discharge is noted at the middle of the flood cycle, which concurs with the flow of a standing tidal wave in a channel flowing against an outgoing discharge. Since the tide acts both to accelerate and decelerate the flow in the channel, the mean calculated flow rate should represent that of the mean flow rate of the PGS discharges. The mean flowrate measured by the ADCP is $22 \mathrm{~m}^{3} / \mathrm{s}$, which is in order-ofmagnitude agreement with the measured discharge of $12-14 \mathrm{~m}^{3} / \mathrm{s}$ during previous sampling events (Flow Science). The 48-hour median filtered estimated flow rate can vary greatly, however, from $10 \mathrm{~m}^{3} / \mathrm{s}$ to $34 \mathrm{~m}^{3} / \mathrm{s}$, and with tidal variations, can vary from almost $0 \mathrm{~m}^{3} / \mathrm{s}$ to 45 $\mathrm{m}^{3} / \mathrm{s}$.

It is apparent from calculations of flow that PGS discharge was particularly high during the latter part of July and the beginning of August. This concurs with temperature data, when average water temperature was highest during this period (Figure 16). In addition, two other periods of higher flow rate correspond to higher water temperature (e.g., at the end of August to the beginning of September, and at the end of September).

Our calculation of the tidal prism flow rate is somewhat higher than the flow rate calculated by the ADCP velocity measurements (which should include the tidal flow). This discrepancy is most likely a function of two factors. First, the mean channel depth is probably shallower than $2.7 \mathrm{~m}$, due to shoaling, resulting in a reduced tidal prism. Second, the application of a parabolic shape to the flow across channel may be an exaggeration, and flow along the sides of the channel may be stronger. In addition, the ADCP may not have been placed exactly in the center of maximum flow, and thus our measurements might underestimate the flow.

The freshwater event noted on 20 September in river discharge is too small to distinguish from tidal and PGS discharge fluctuations. An event in freshwater discharge around 5 August noted in the combined downstream discharge data (Figure 15) did correspond to a higher calculated flow rate from the ADCP data. However, there was no corresponding reduction in 
salinity from any of the three sites, so it is impossible to state whether this measured flow was due to a peak in river input. Nevertheless, the 20 September event did not appear to have a significant effect on the overall circulation within the estuary, as the PGS discharge dominates the flow during this time of year.

\section{Summary}

The oceanographic data collected by the USGS show that in the warm, dry summer season, the flow in the SGR estuary is dominated by the cooling water discharge from the natural-gas PGS. Several CTD surveys over the course of the summer revealed that the water column remains vertically mixed downstream of the discharges, and stratified by both temperature and salinity upstream. Time-series analysis of temperature and salinity measurements at the surface and bottom at several locations up- and downstream of the discharges confirm the results of the synoptic CTD surveys. Temperature showed predominantly diurnal variability in both surface and bottom layers, which is most likely due to the diurnal variability in PGS discharge. Salinity showed both semidiurnal and diurnal variability indicative of the mixed tide of southern California, and the lack of a notable salinity front downstream of the PGS discharge suggests this is due to mixing of ocean and river waters on a tidal basis. There was one notable freshwater rain event during the period of instrument deployment which reduced salinity to zero upstream and by a factor of 2 downstream of the discharges. Temperature and salinity returned to levels observed prior to the event within a few tidal cycles.

Flow upstream of the discharge was weak and varied in magnitude and direction with the tides, and the degree of stratification did not have a significant effect on the flow. Downstream of the discharge currents were strong, flowing consistently outward toward the ocean, and varied in magnitude but not direction with the tidal height. Peak velocity was noted at the end of the ebb, when the PGS, river and tidal discharge combine into one flow. Vertical shear in the alongchannel currents was noted upstream of the discharge, while currents were mostly uniform throughout the water column downstream.

A calculation of total discharge in the river from ADCP measurements shows that the PGS discharge is approximately 5 times that of the river input at this time of year, and the freshwater event in late September was indistinguishable from PGS discharge levels. A peak in the spectral energy of both velocity and pressure near 1 hour suggests the presence of a seiche within the estuary, but it is not clear what would force a seiche at this frequency.

Since the data from this study focus on the summer dry season, these conclusions do not necessarily apply to winter conditions, when river discharge is considerably higher (and more episodic). We might expect electricity usage to vary over the course of the year, potentially being less in winter due to less air conditioning usage, and thus the PGS discharge might be less. Higher input of freshwater would most likely induce an estuarine style of circulation with strong outflow on the surface and a subsequent return flow up estuary in the bottom, increasing vertical shear in the water column. 


\section{References}

Flow Science, 2005. Lower San Gabriel Data Analysis Data Report.

Fofonoff, P. and Millard, R.C. Jr, 1983. Algorithms for computation of fundamental properties of seawater. UNESCO Tech. Paper in Marine Science, no. 44, 53 p.

Pond, G.L. and Pickard, S., 1983. Introductory dynamical oceanography. Elsevier ButterworthHeinemann, Oxford, UK, 352 p. 


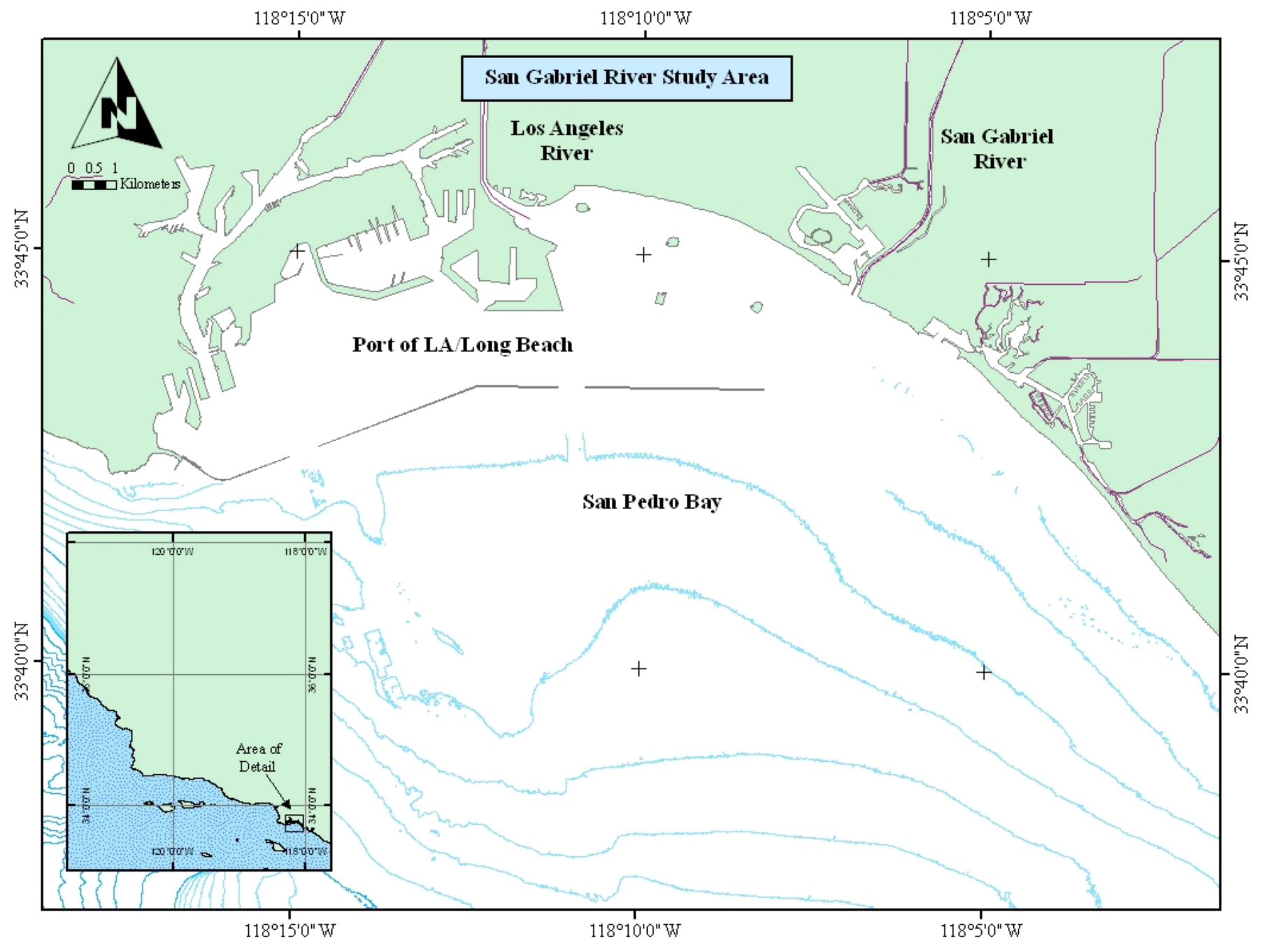

Figure 1. Overview map of study area with position of San Gabriel River within the Southern California Bight. 


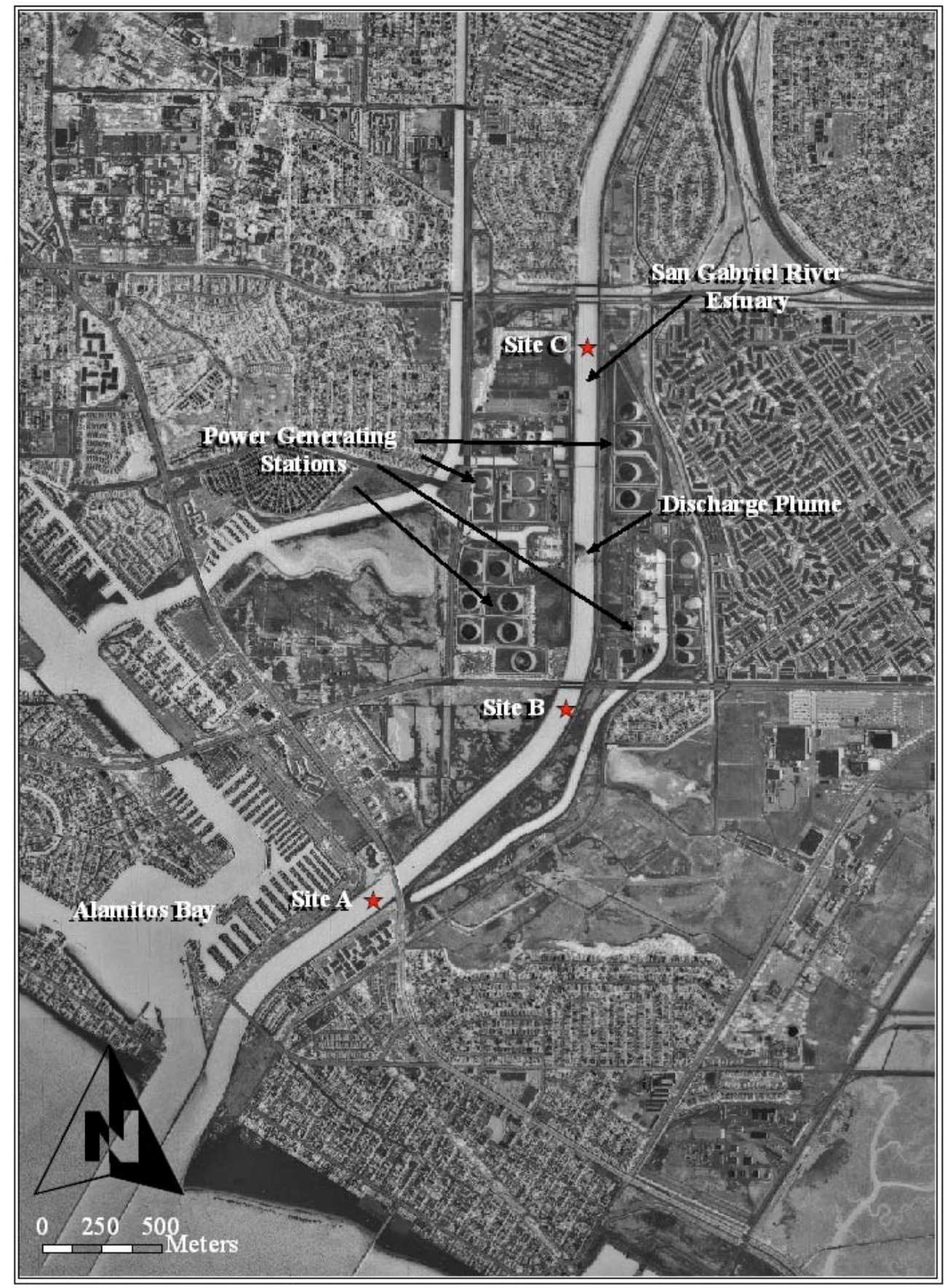

Figure 2. Digital orthophoto of San Gabriel River estuary 


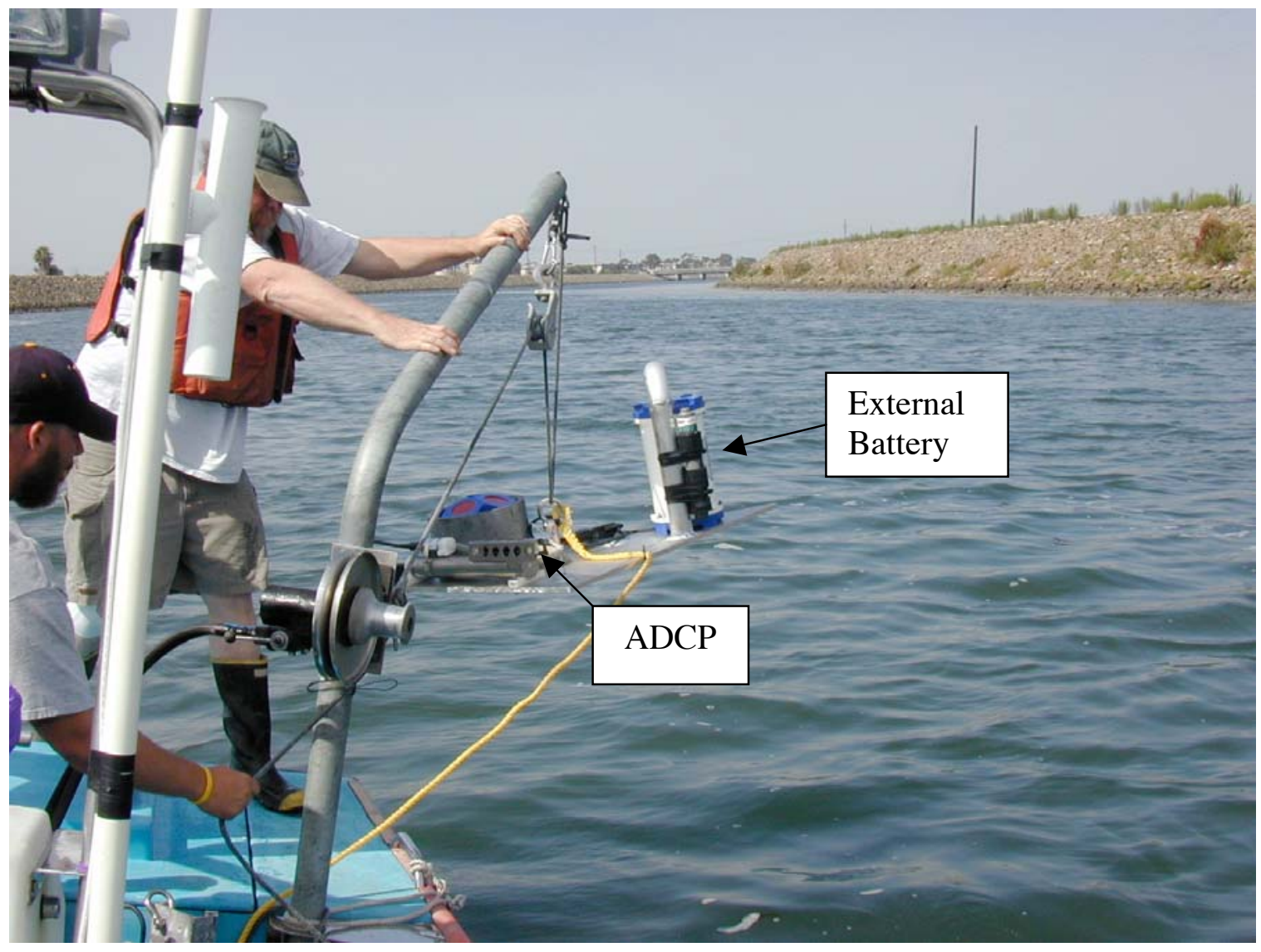

Figure 3. Photo of deployment of bottom platform for RD Instruments current meter at Site B. The yellow line trailing off towards the bow is the recovery ground line. 


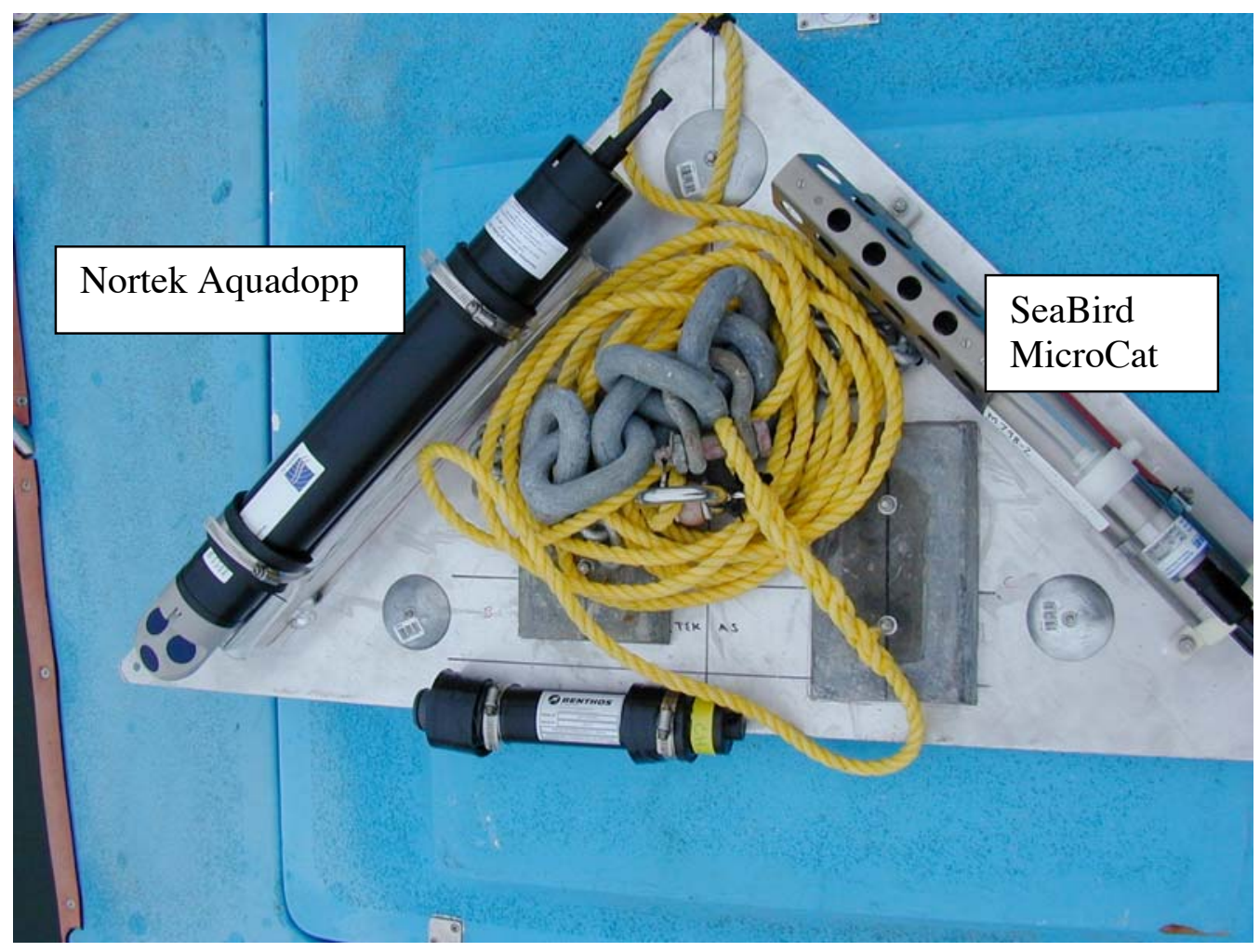

Figure 4. Photo of bottom platform for Nortek Aquadopp current meter at Site C. 


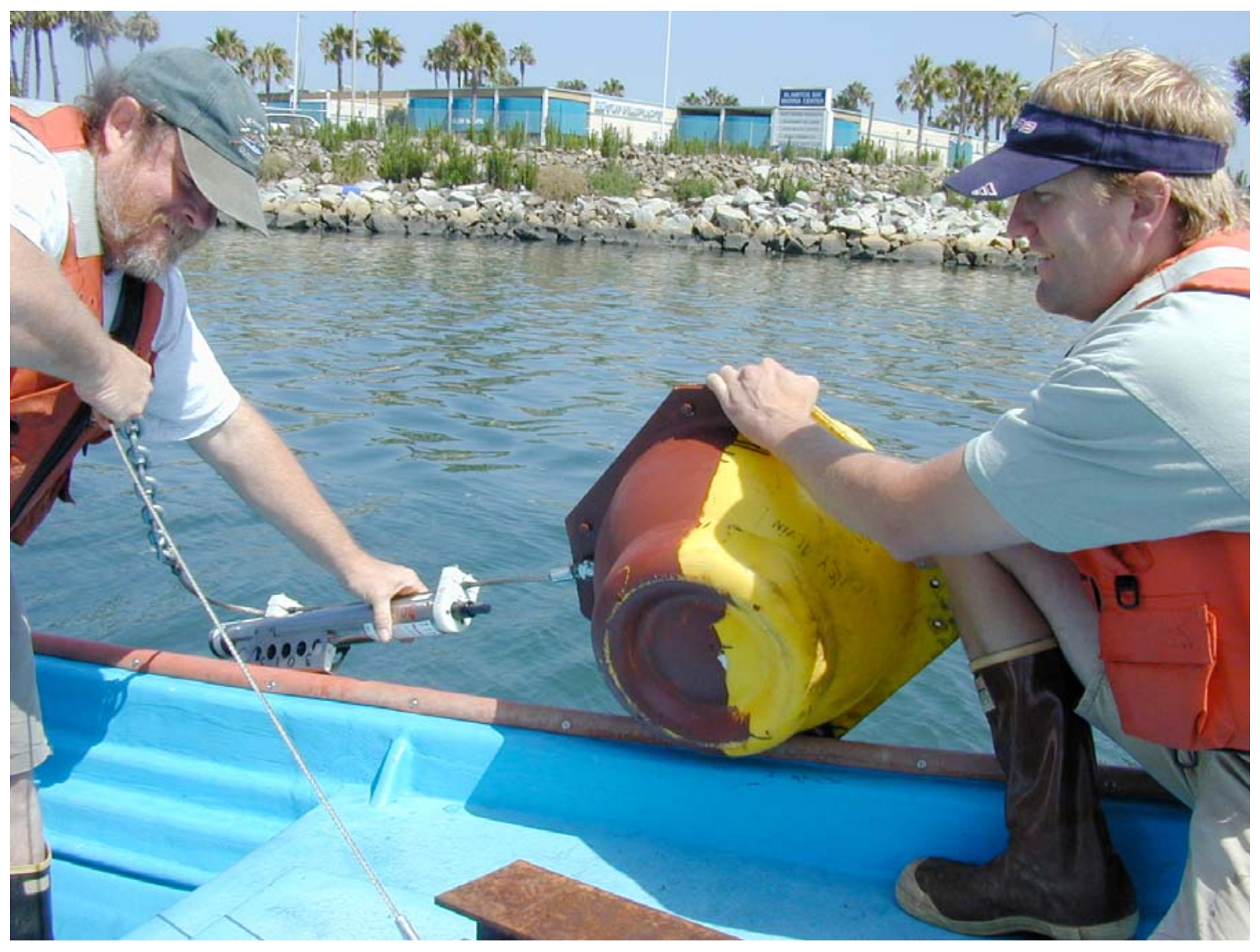

Figure 5. Photo of deployment of surface mooring with Microcat. 


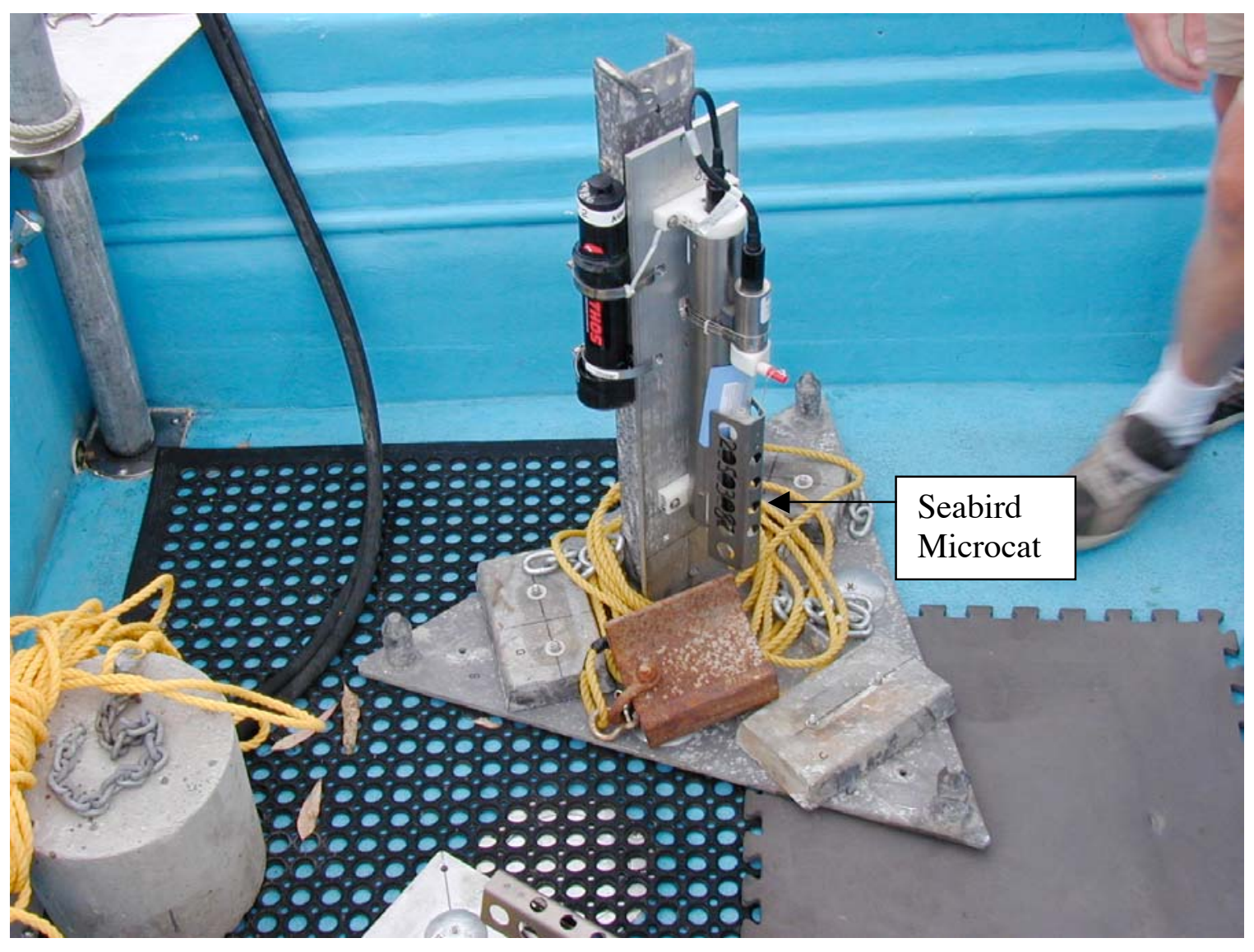

Figure 6. Photo of bottom platform for Seabird Microcat at Site A. 


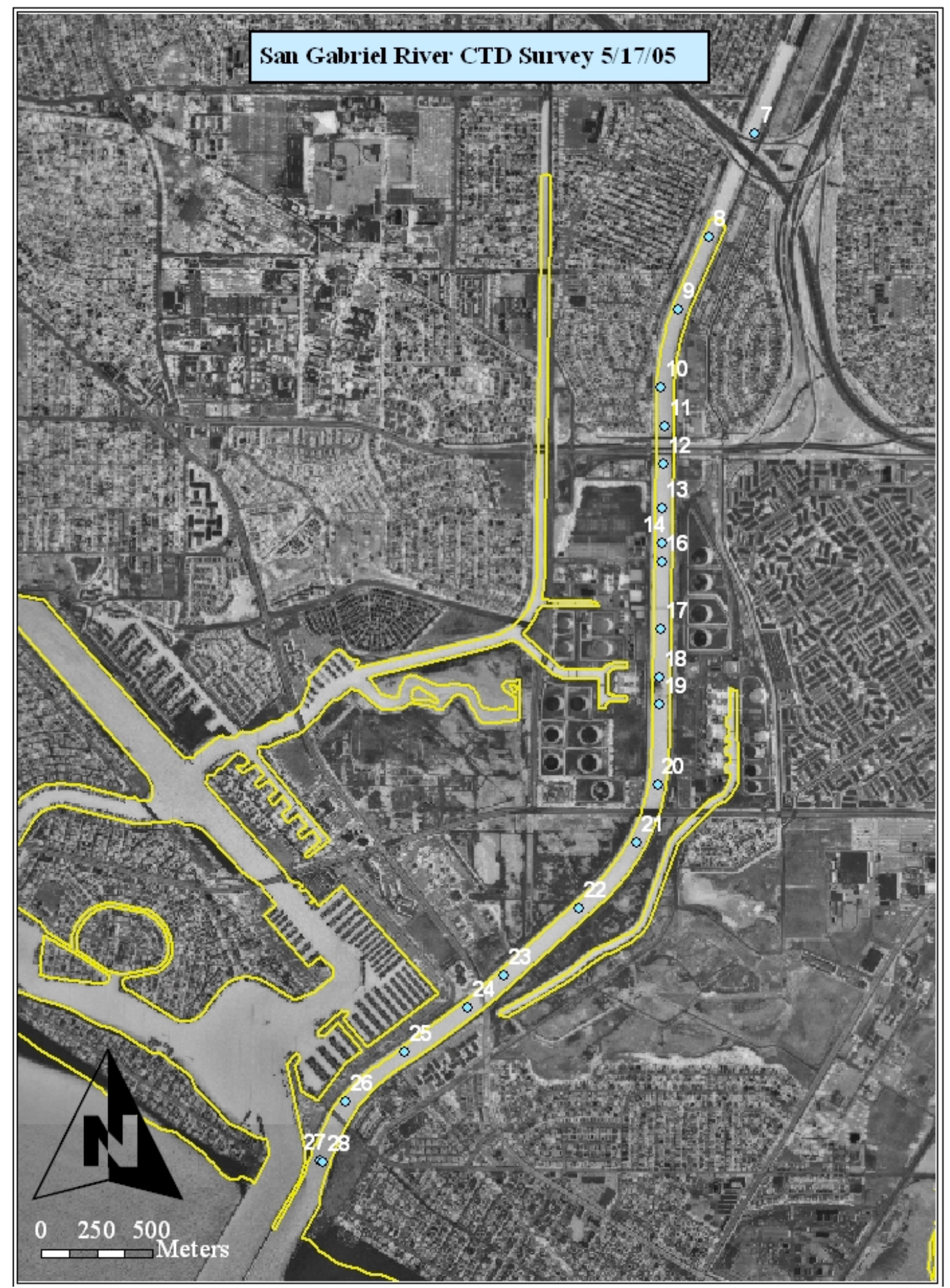

Figure 7. Map of locations of CTD casts taken during scoping survey on 17 May 2005. 


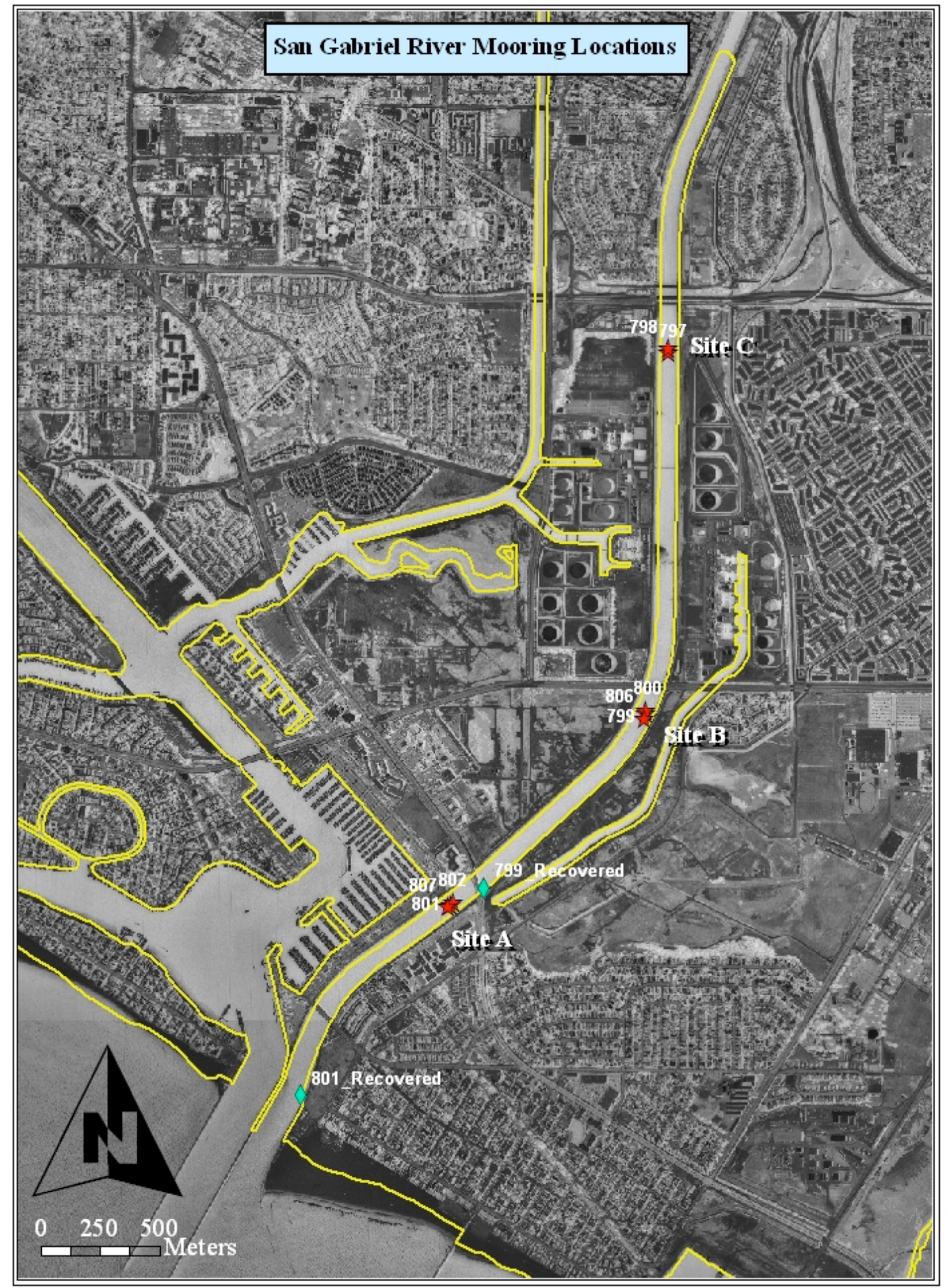

Figure 8. Map of final deployment locations of all moored platforms. The recovery locations of the two surface moorings that moved during deployment are shown in green diamonds. 


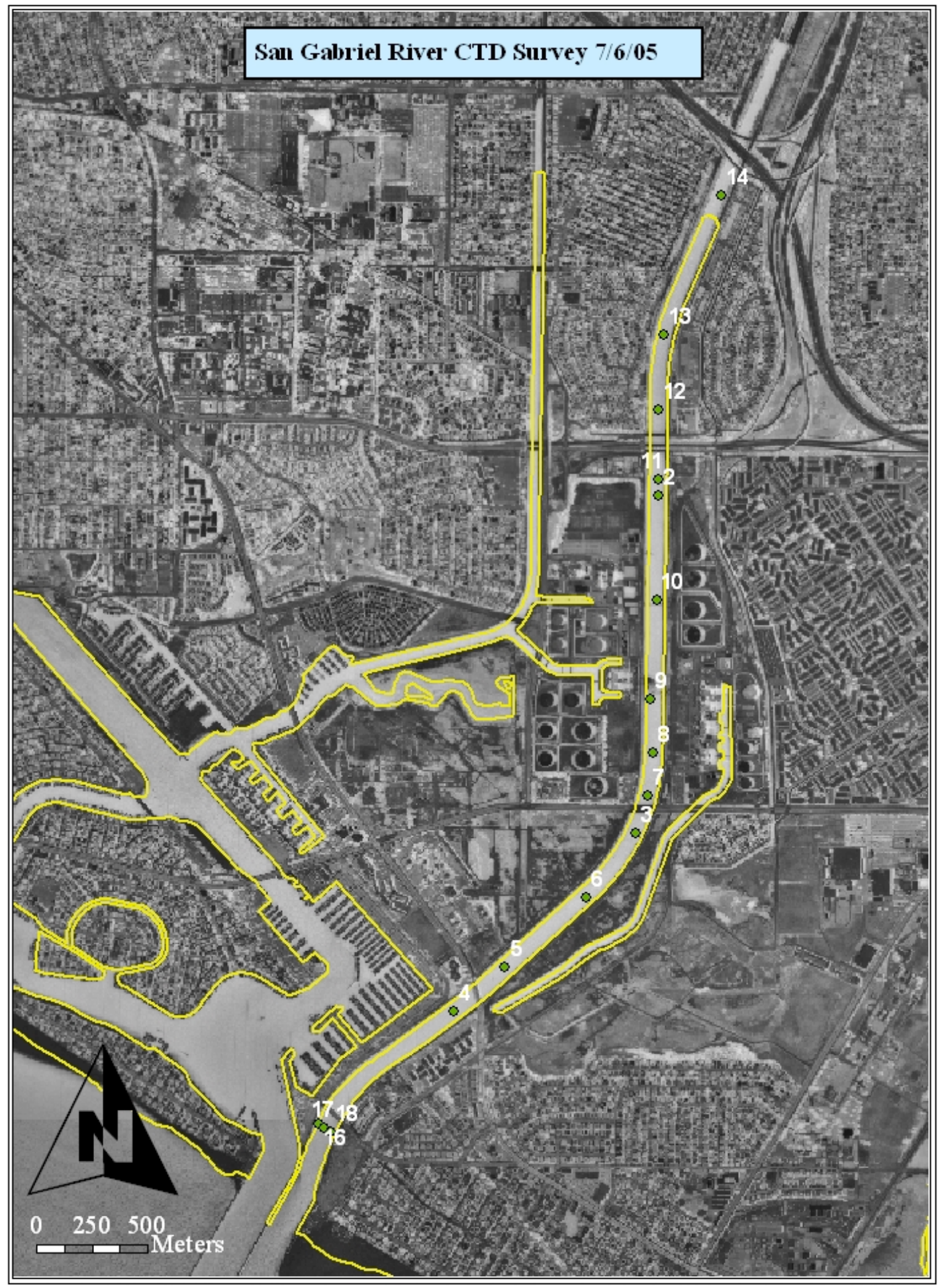

Figure 9. Map of locations of CTD casts taken during deployment on 6 July 2005. 


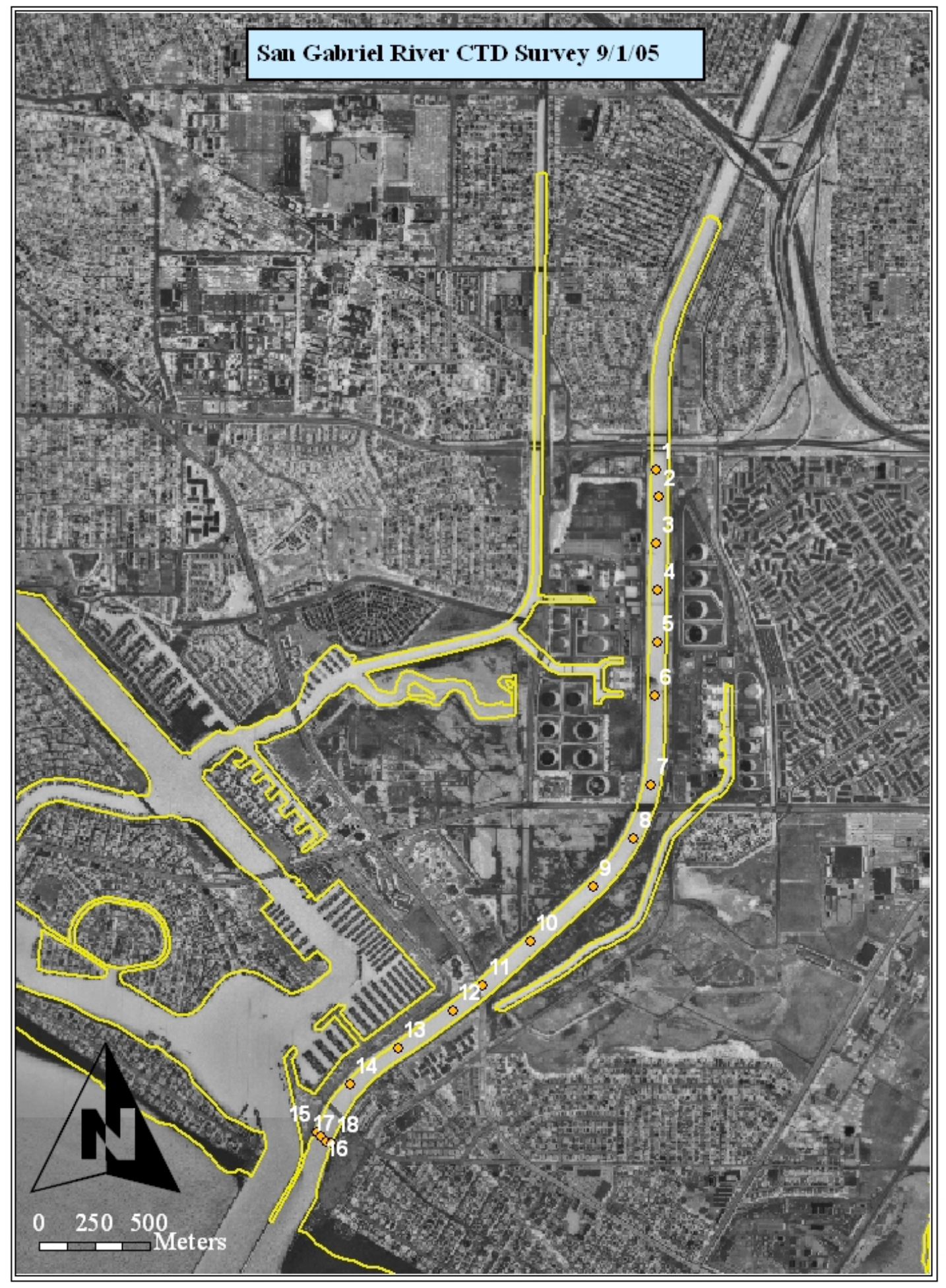

Figure 10. Map of locations of CTD casts taken during turnaround survey on 1 September 2005. 


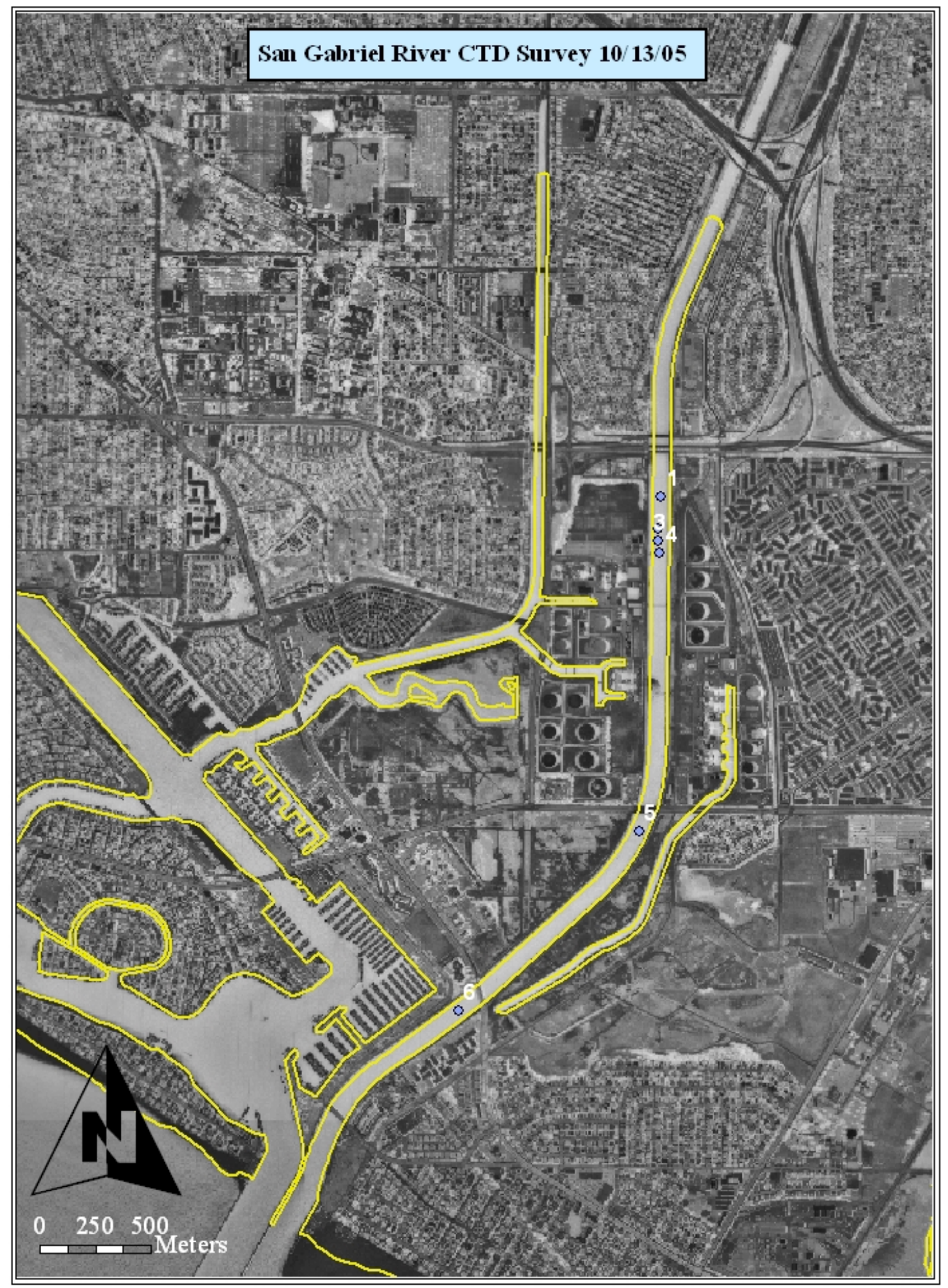

Figure 11. Map of locations of CTD casts taken during recovery on 13 October 2005. 


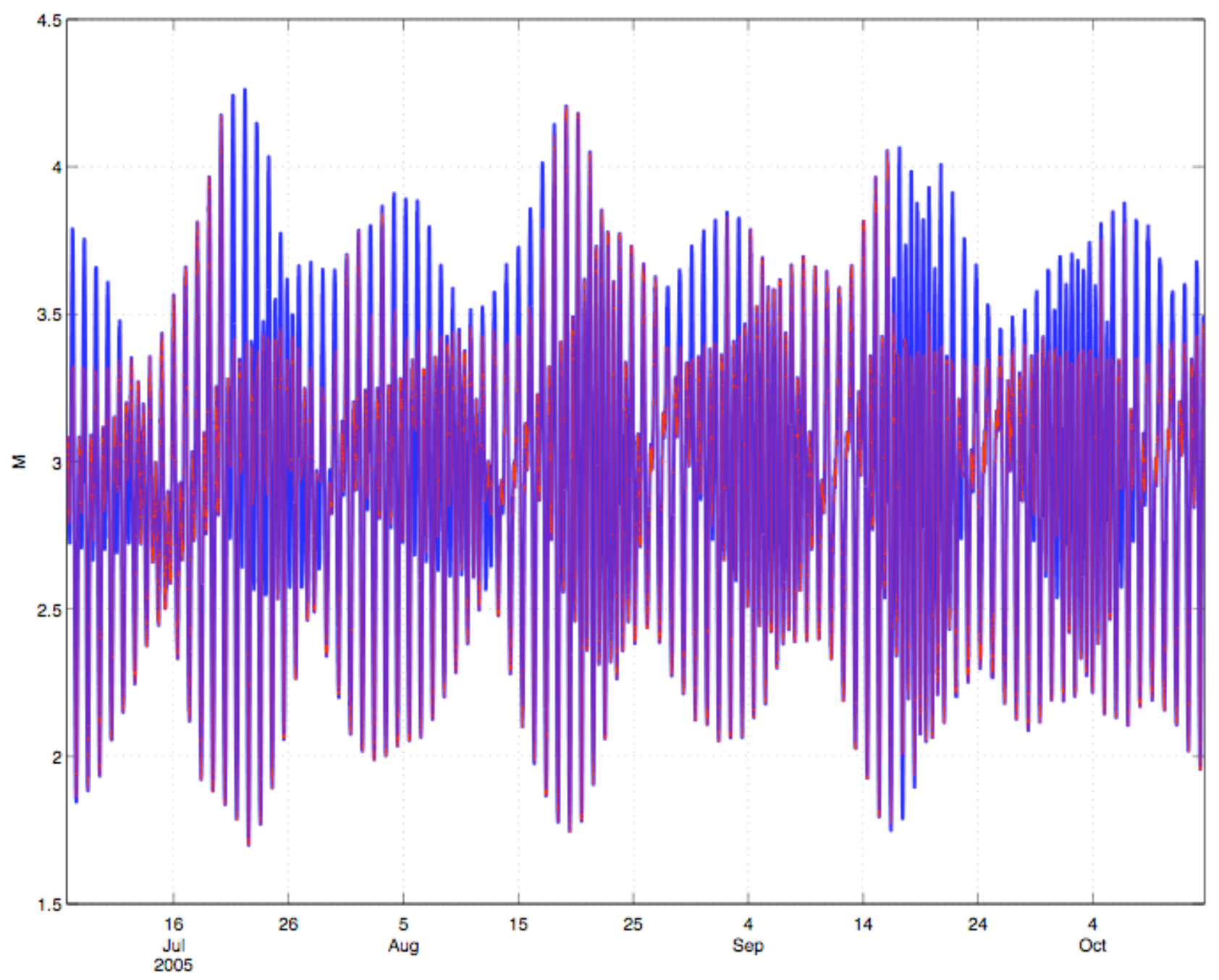

Figure 12. Time series of water level (blue) and water level when bad data at ADCP Site B occurred (red). 

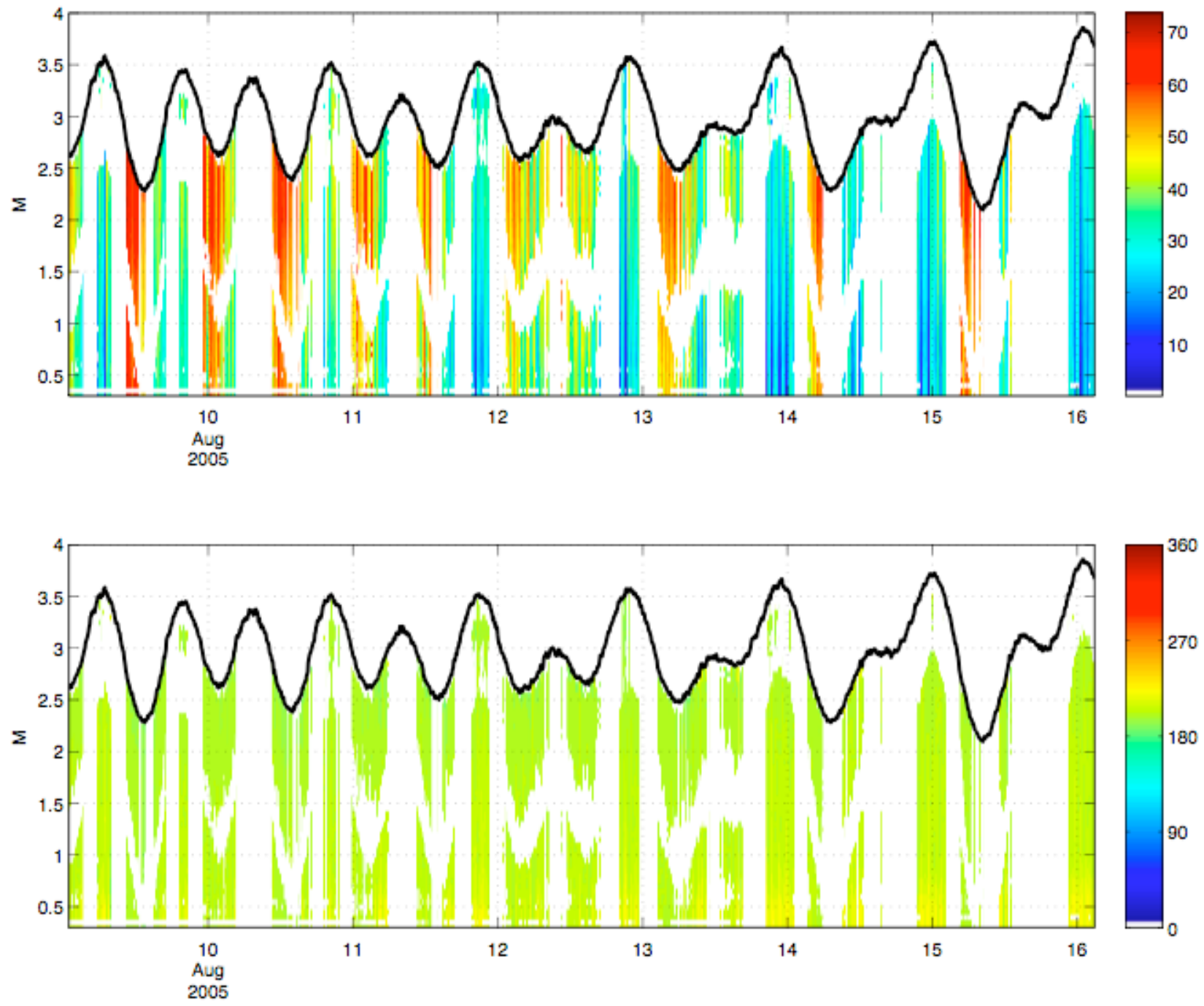

Figure 13. One-week time series of current speed and direction at Site B, with water level overplotted (black line). 


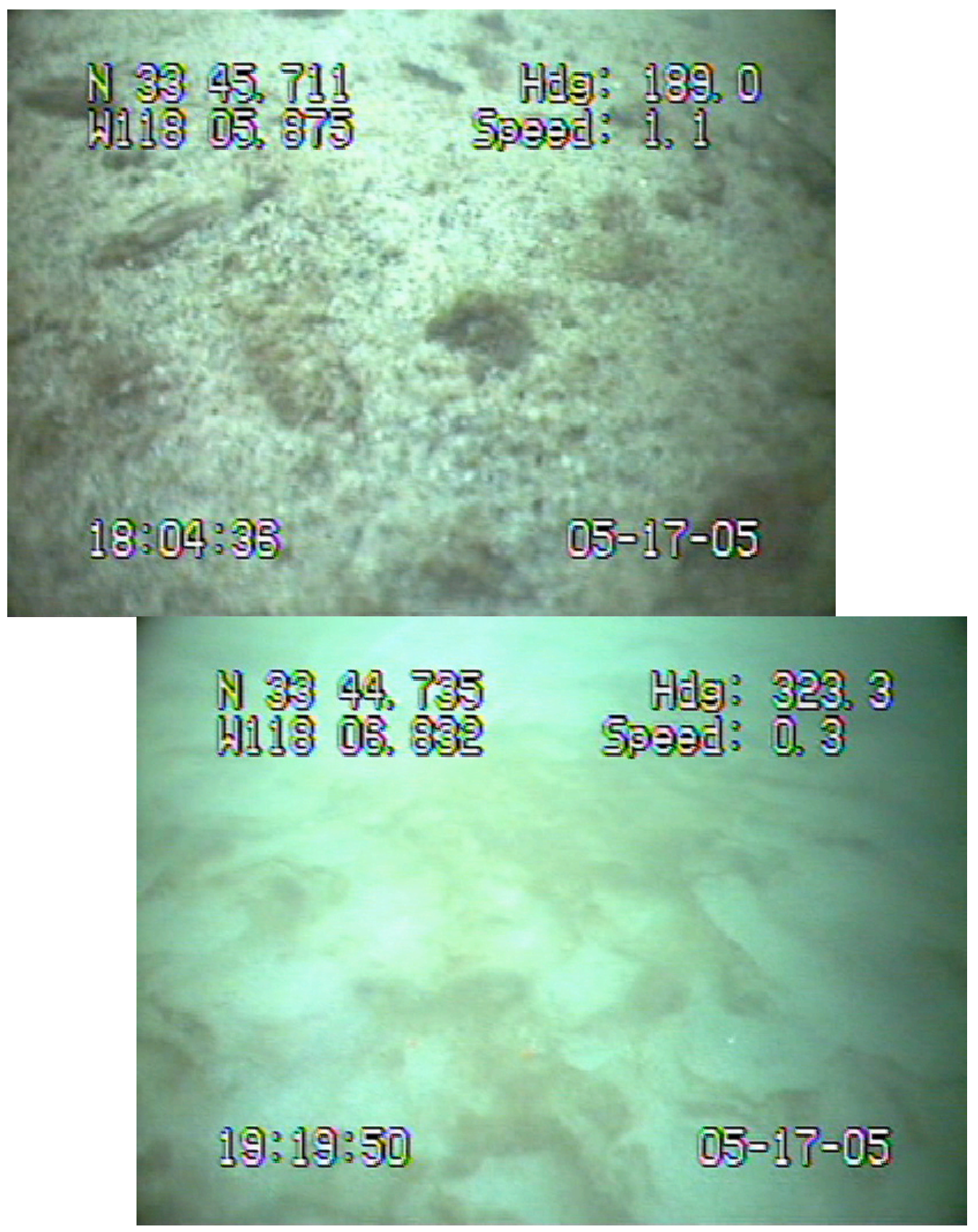

Figure 14. Still frame examples from video camera sled survey on 17 May 2005. 


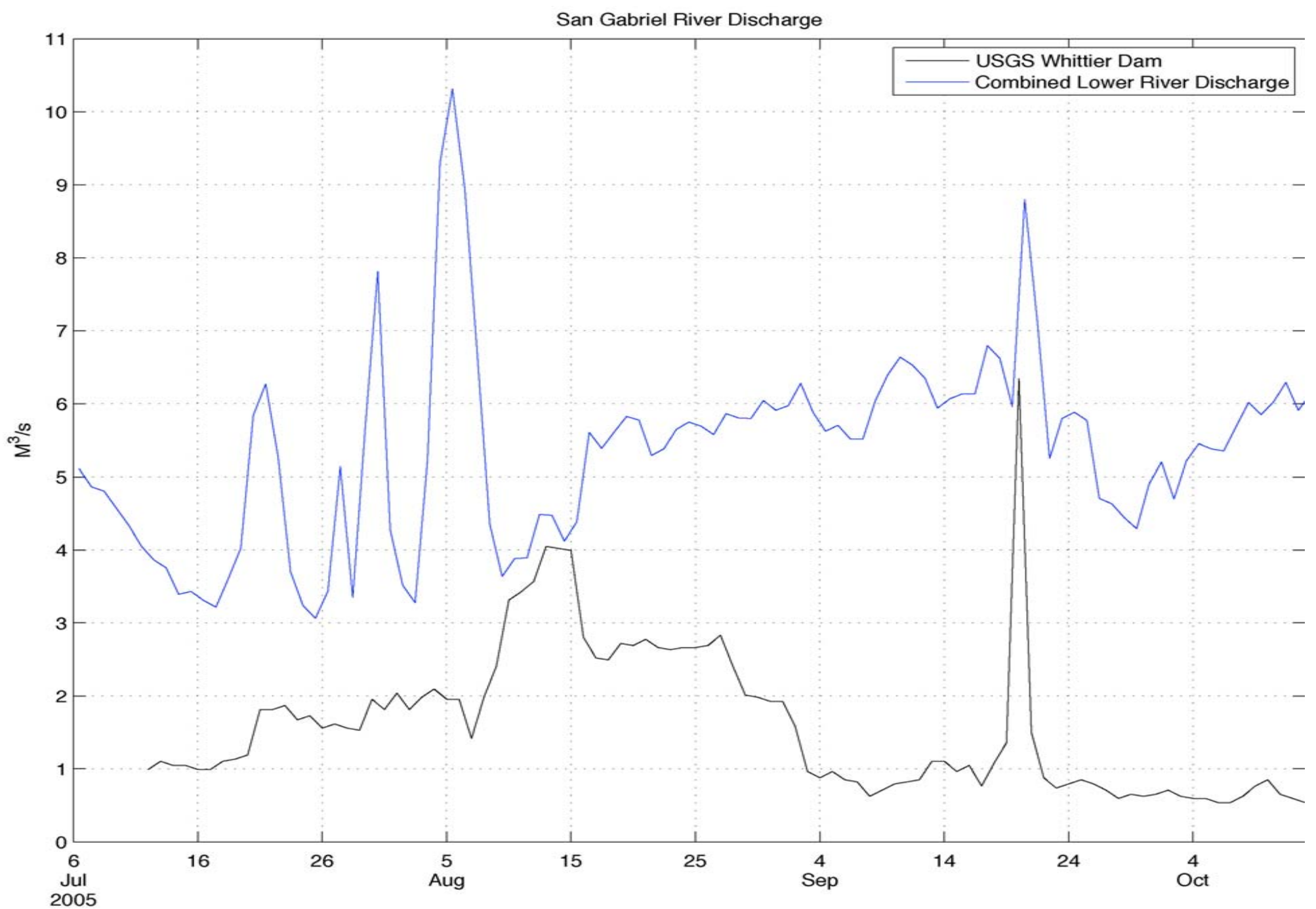

Figure 15. Time series of San Gabriel River discharge from Whittier Dam stream gauge and the combined flow measured at the lower SGR, Coyote Creek, and LACSD Long Beach Treatment Plant. 


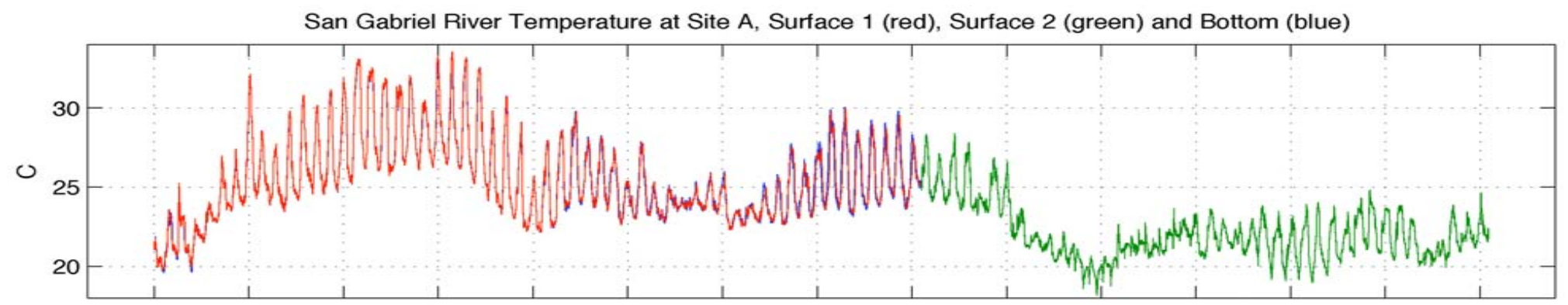

San Gabriel River Salinity at Site A, Surface 1 (red), Surface 2 (green) and Bottom (blue)

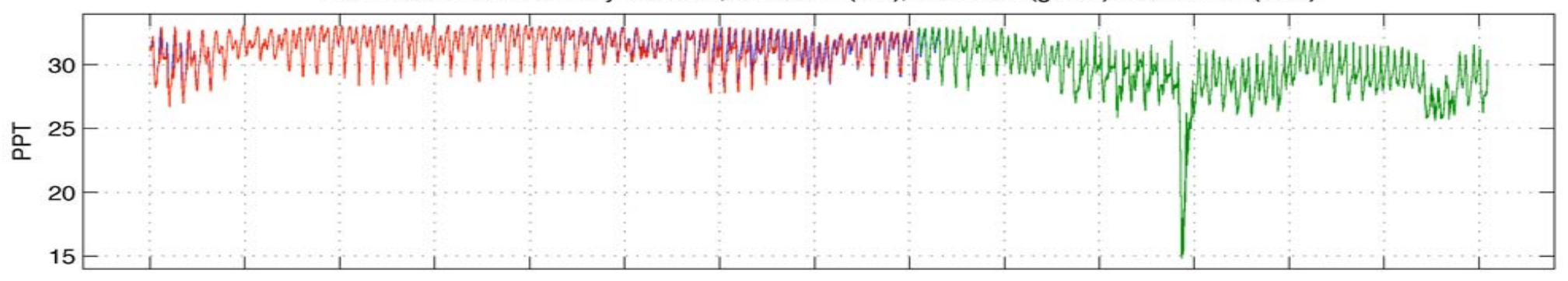

San Gabriel River Density at Site A, Surface 1 (red), Surface 2 (green) and Bottom (blue)

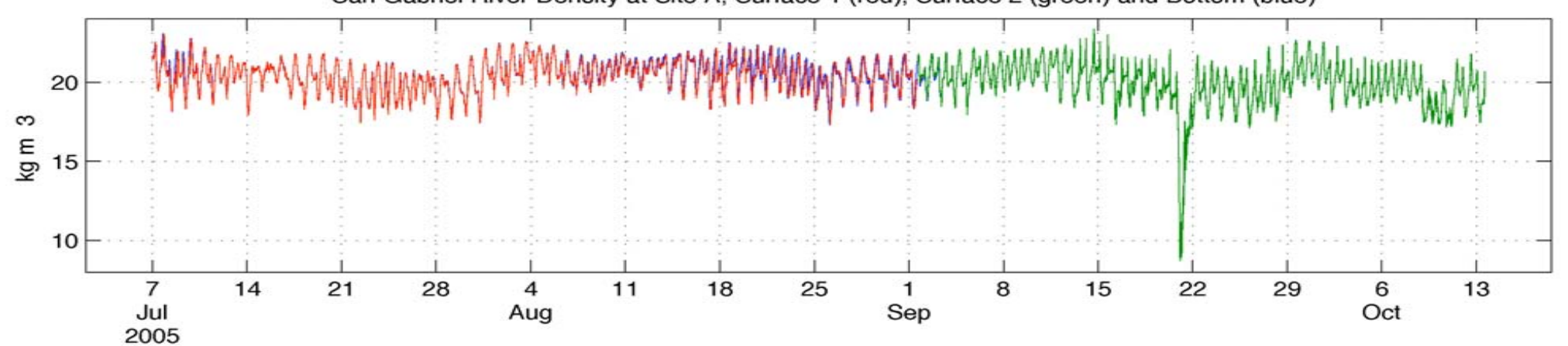

Figure 16. Time series of temperature (top panel), salinity (middle panel) and density (bottom panel) at Site A as recorded by moored Microcat $\mathrm{T} / \mathrm{S}$ sensors. The surface data is plotted in red (first deployment) and green (second deployment) and bottom data is in blue. 


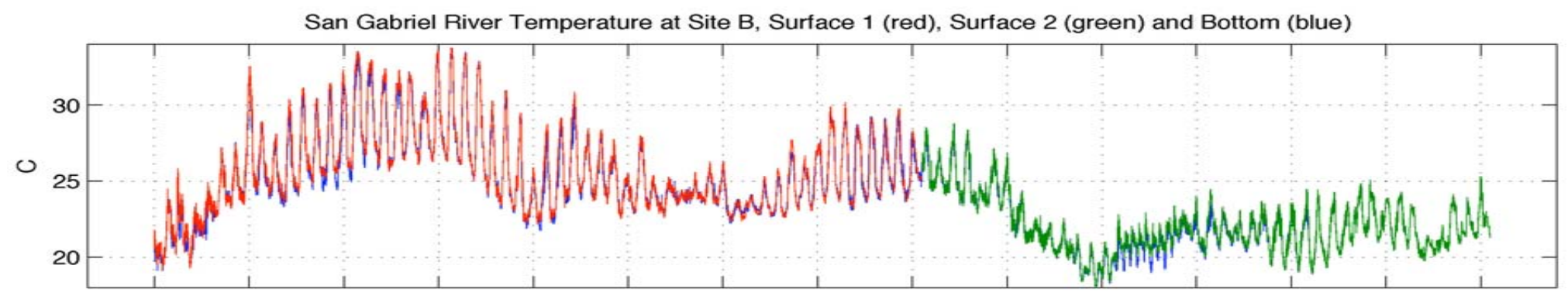

San Gabriel River Salinity at Site B, Surface 1 (red), Surface 2 (green) and Bottom (blue)

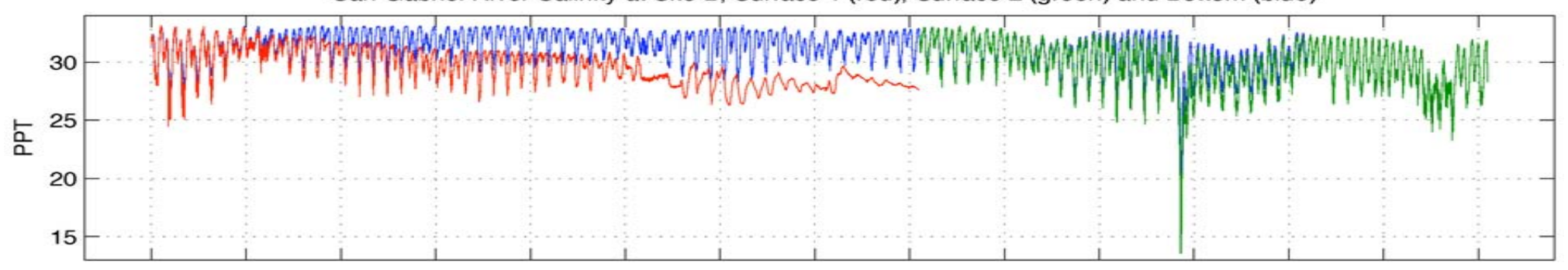

San Gabriel River Density at Site B, Surface 1 (red), Surface 2 (green) and Bottom (blue)

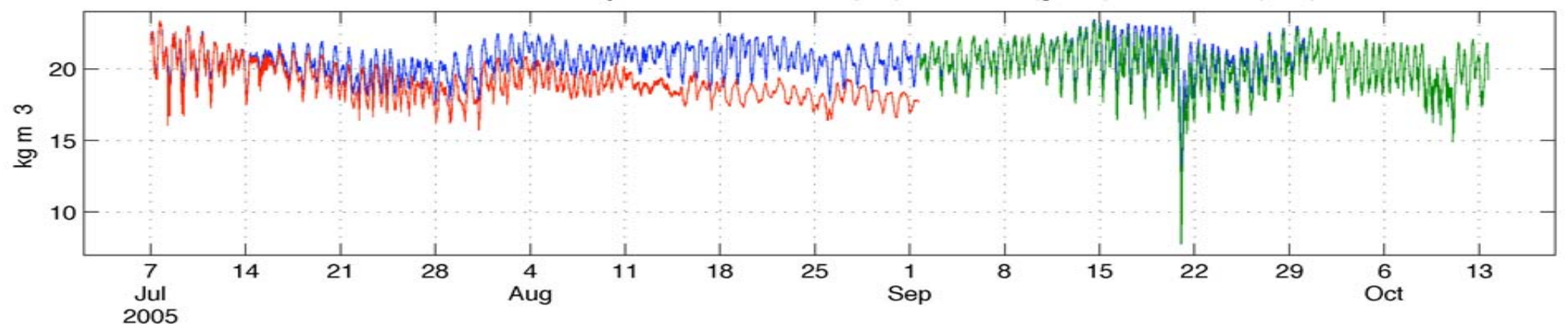

Figure 17. Time series of temperature (top panel), salinity (middle panel) and density (bottom panel) at Site B as recorded by moored Microcat T/S sensors. The surface data is plotted in red (first deployment) and green (second deployment) and bottom data is in blue. 

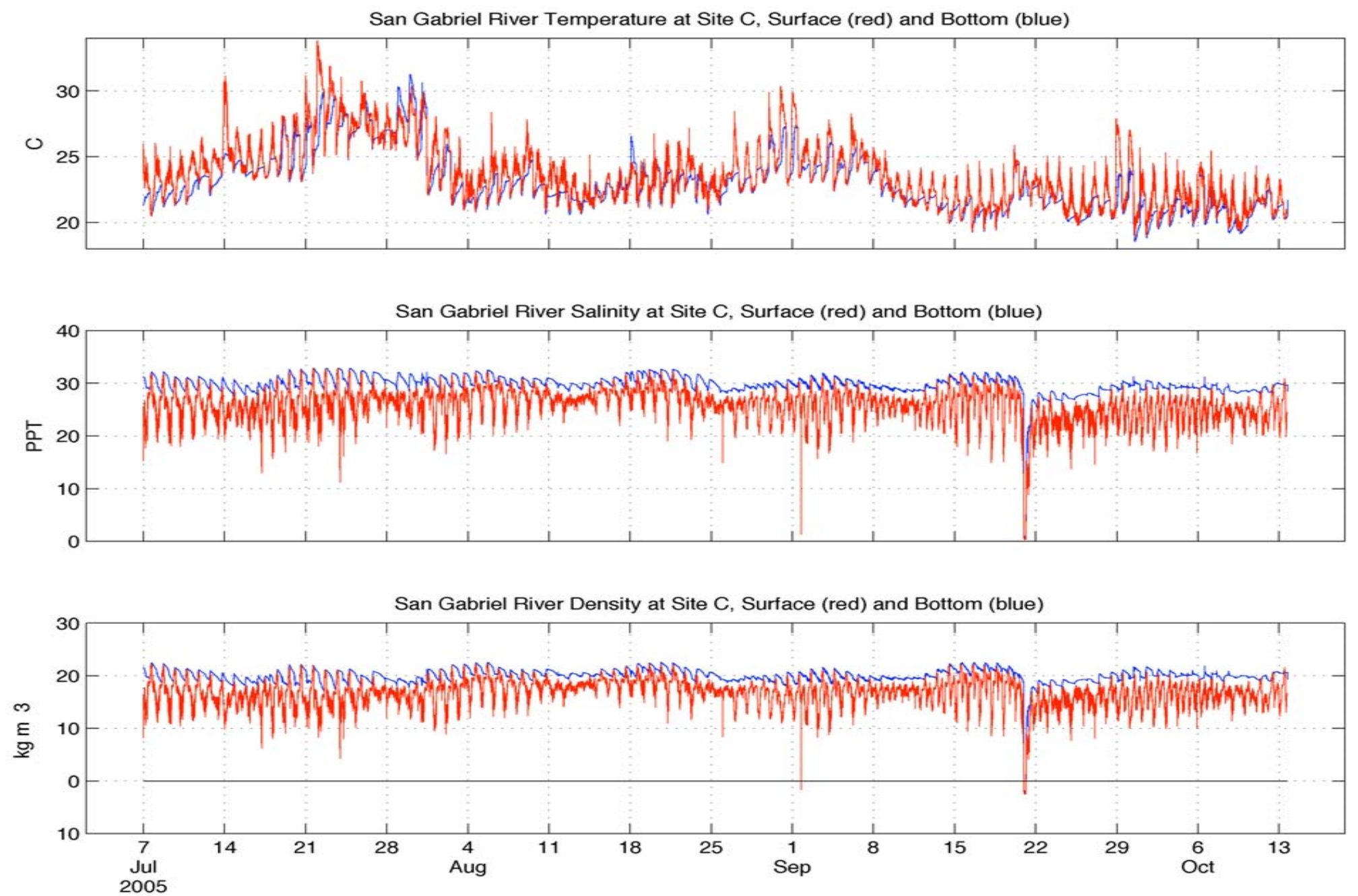

Figure 18. Time series of temperature (top panel), salinity (middle panel) and density (bottom panel) at Site C as recorded by moored Microcat T/S sensors. The surface data is plotted in red and bottom data is in blue. 

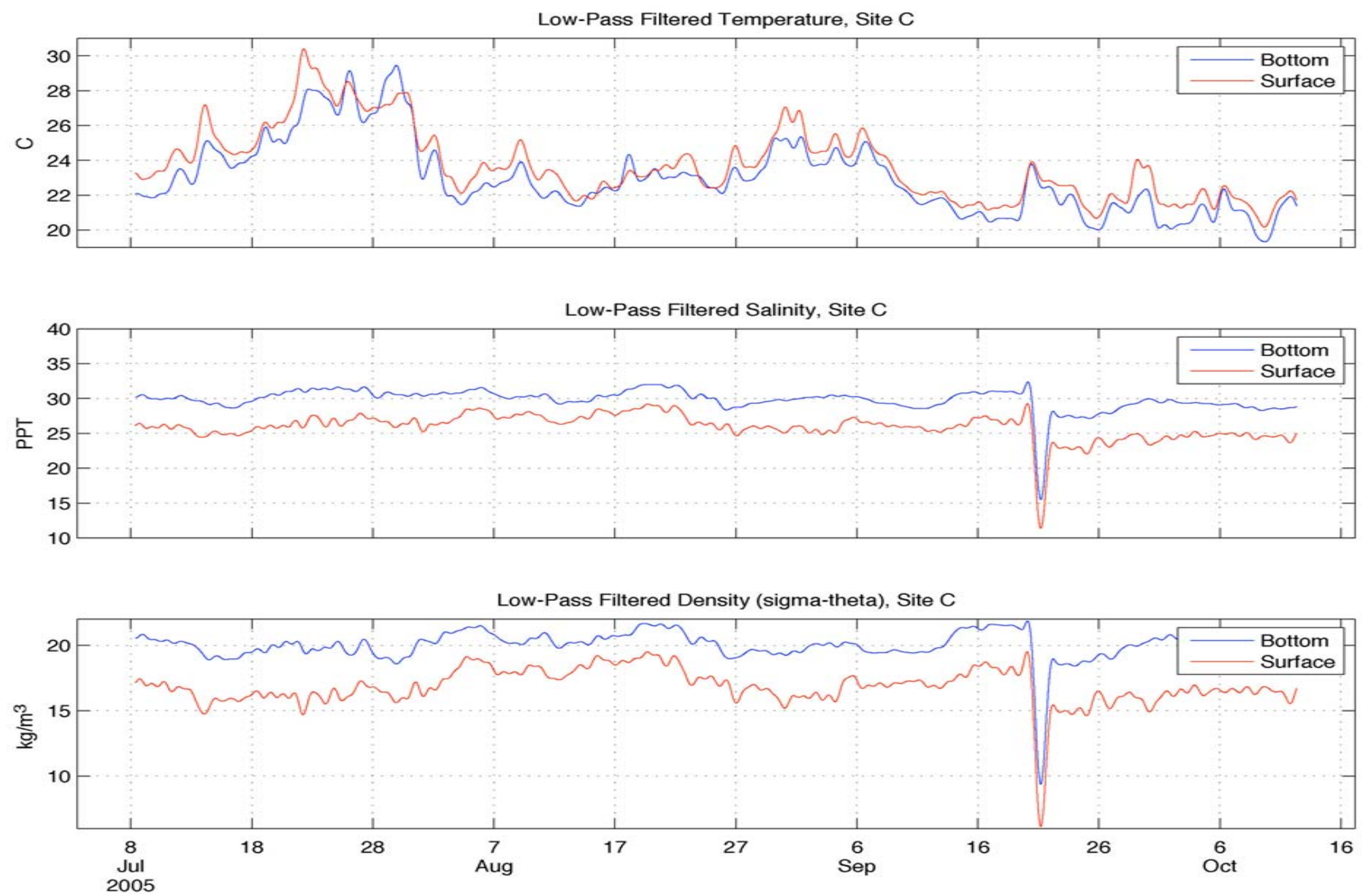

Figure 19. Low-pass filtered time series of temperature, salinity, and density at Site C, surface (red) and bottom (blue). 

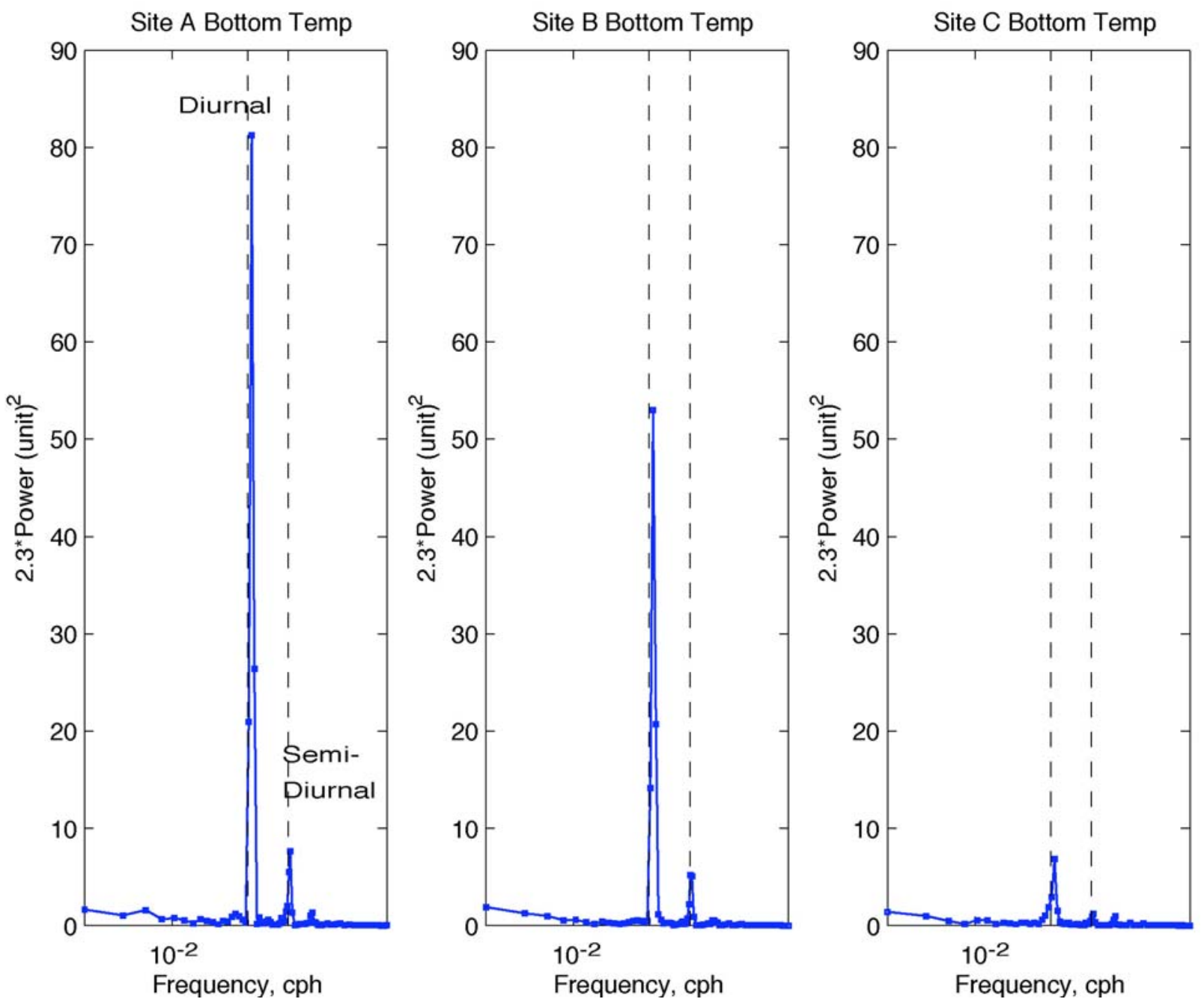

Figure 20. Variance-preserving power spectra of bottom temperature recorded by Microcat at each site. Dashed lines represent primary diurnal and semidiurnal tidal frequencies. 

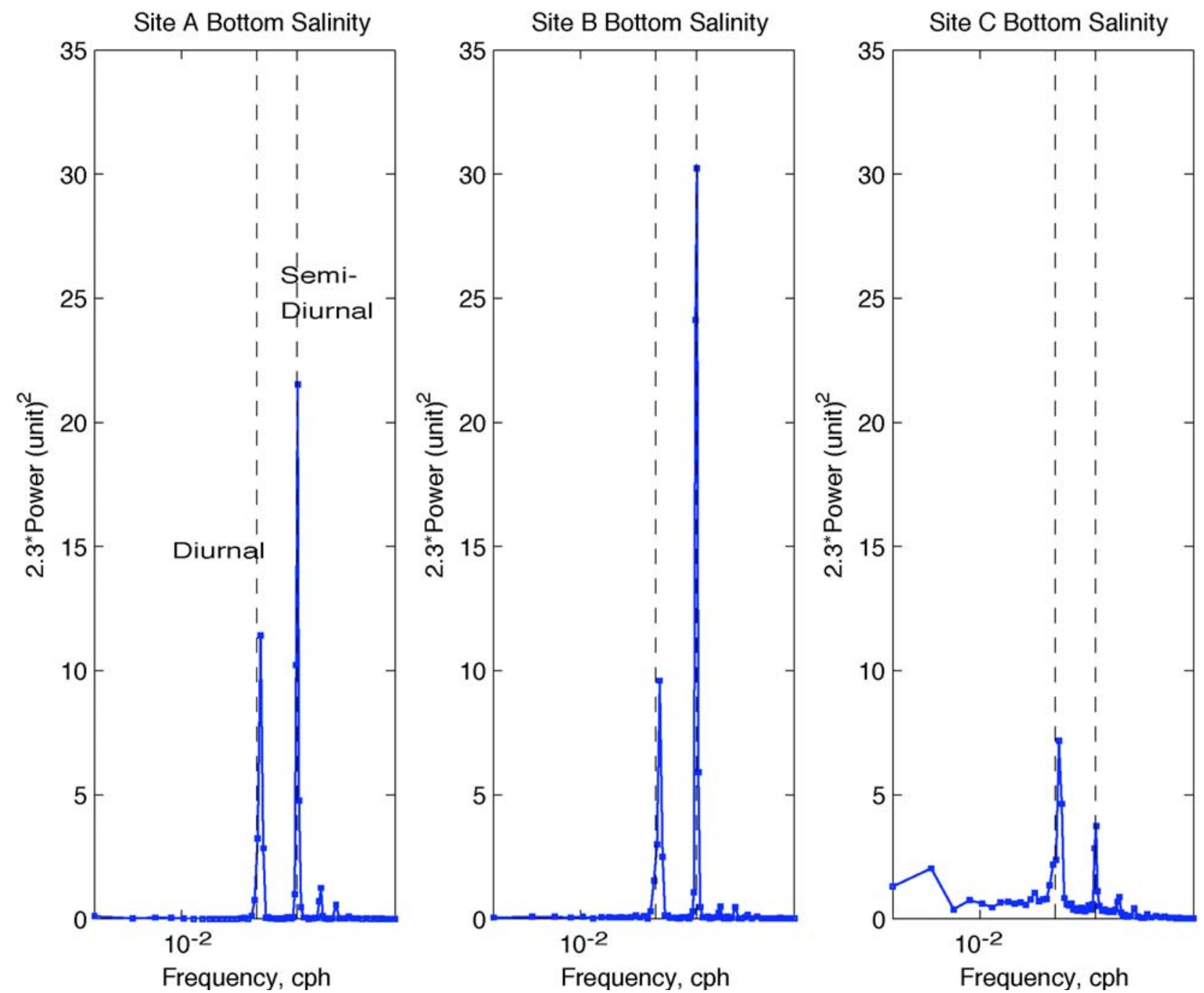

Figure 21. Variance-preserving power spectra of bottom salinity recorded by Microcat at each site. Dashed lines represent primary diurnal and semidiurnal tidal frequencies. 

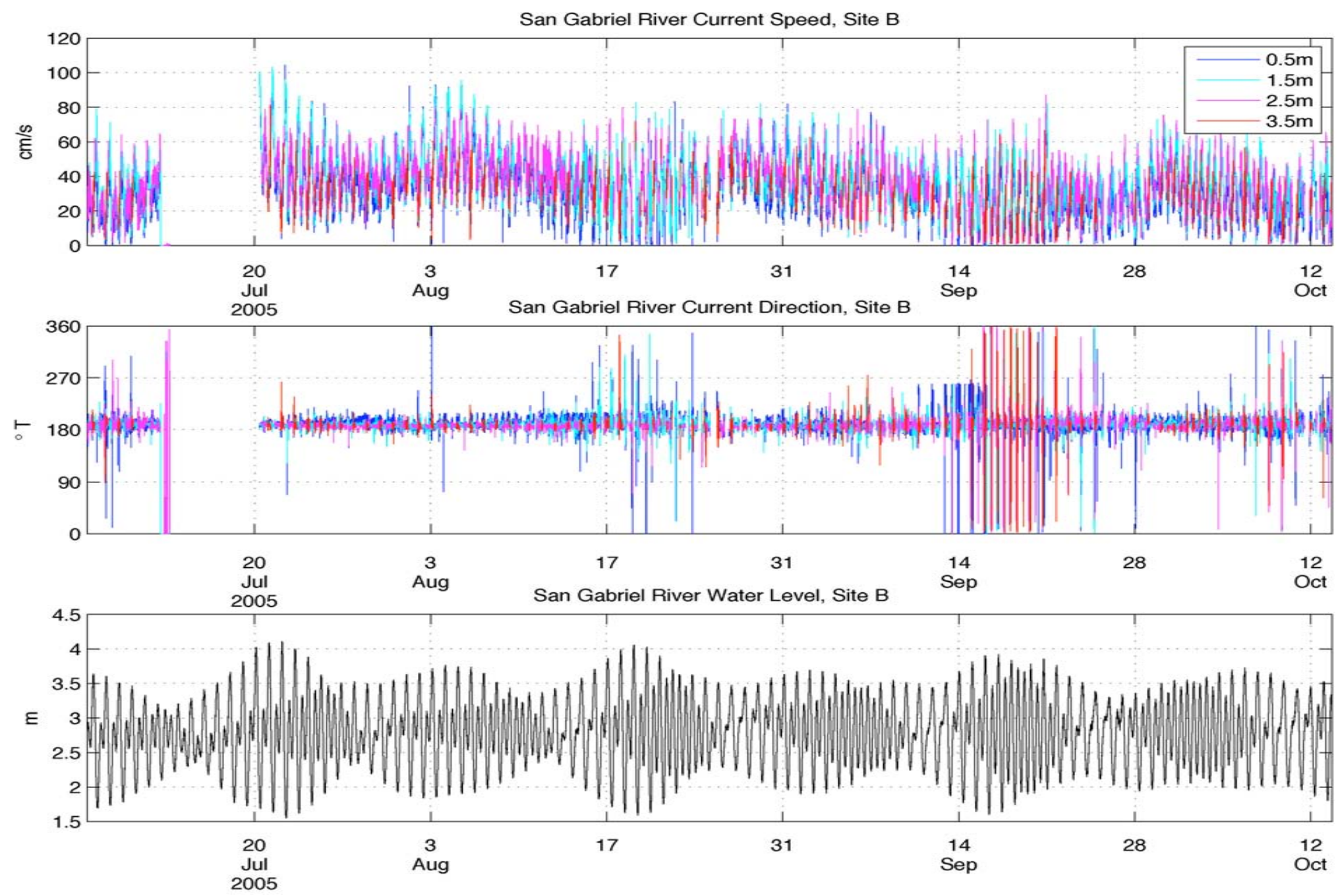

Figure 22. Time series of current speed (top panel), direction (middle panel), and water level (bottom panel) at several depths as recorded by ADCP at Site B. 

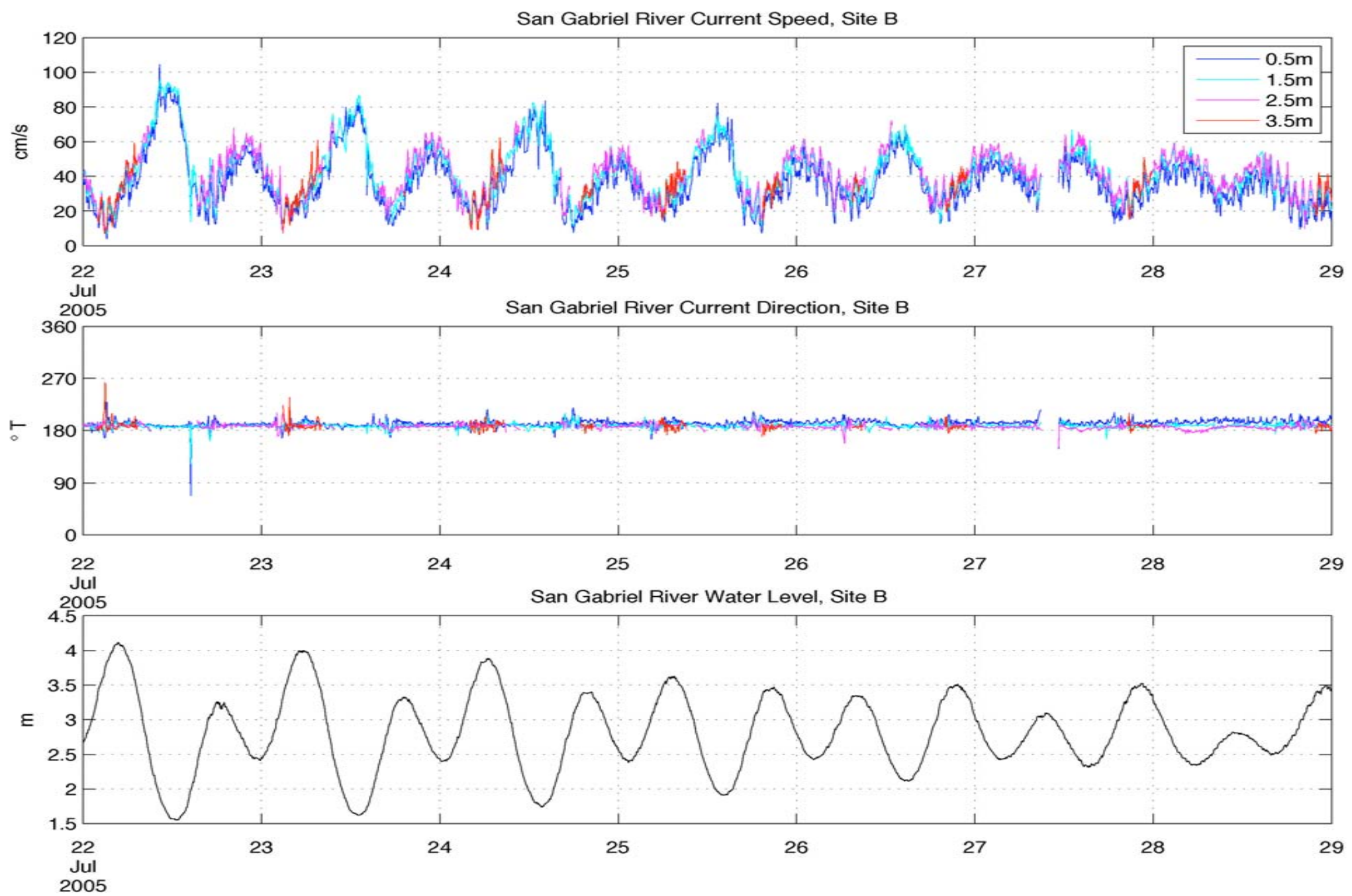

Figure 23. Time series of current speed (top panel), direction (middle panel) and water level (bottom panel) at several depths (listed as distance above the bed) as recorded by ADCP at Site B, for one week of deployment. 

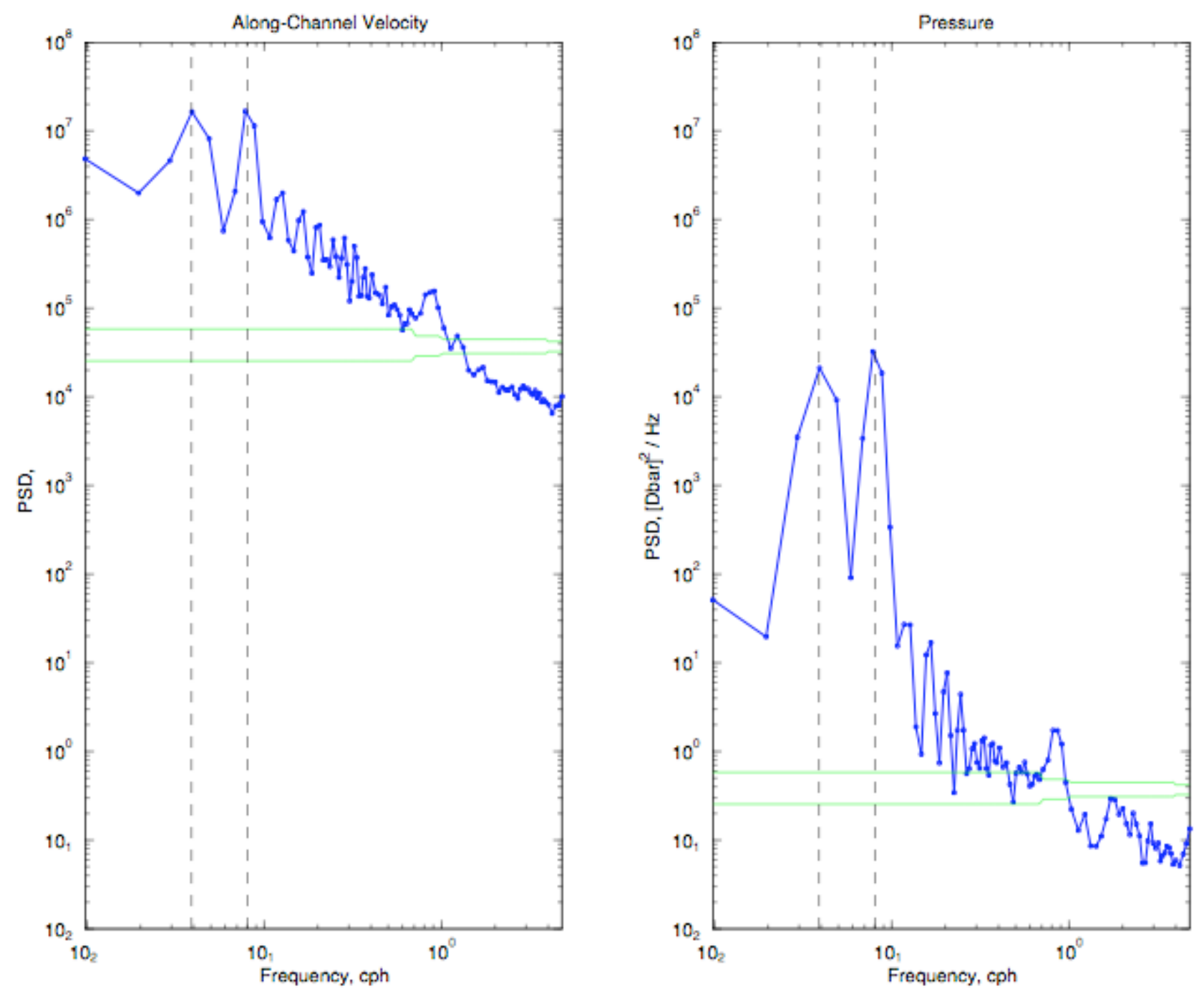

Figure 24. Power spectra of along-channel velocity (left) and pressure (right) at Site B. 

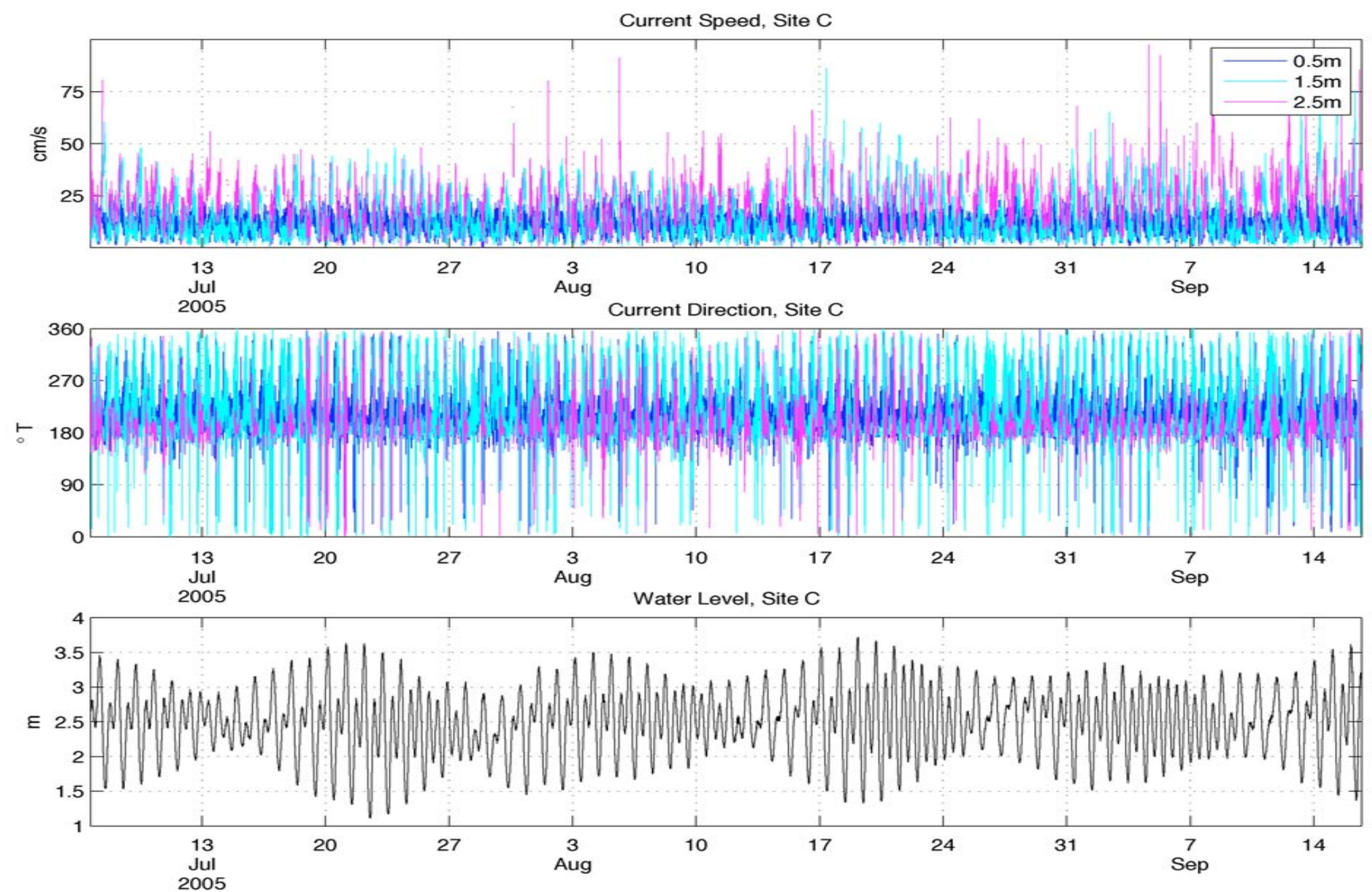

Figure 25. Time series of current speed, direction and water level at several depths as recorded by Nortek Aquadopp at Site C. 
Current Speed, Site C
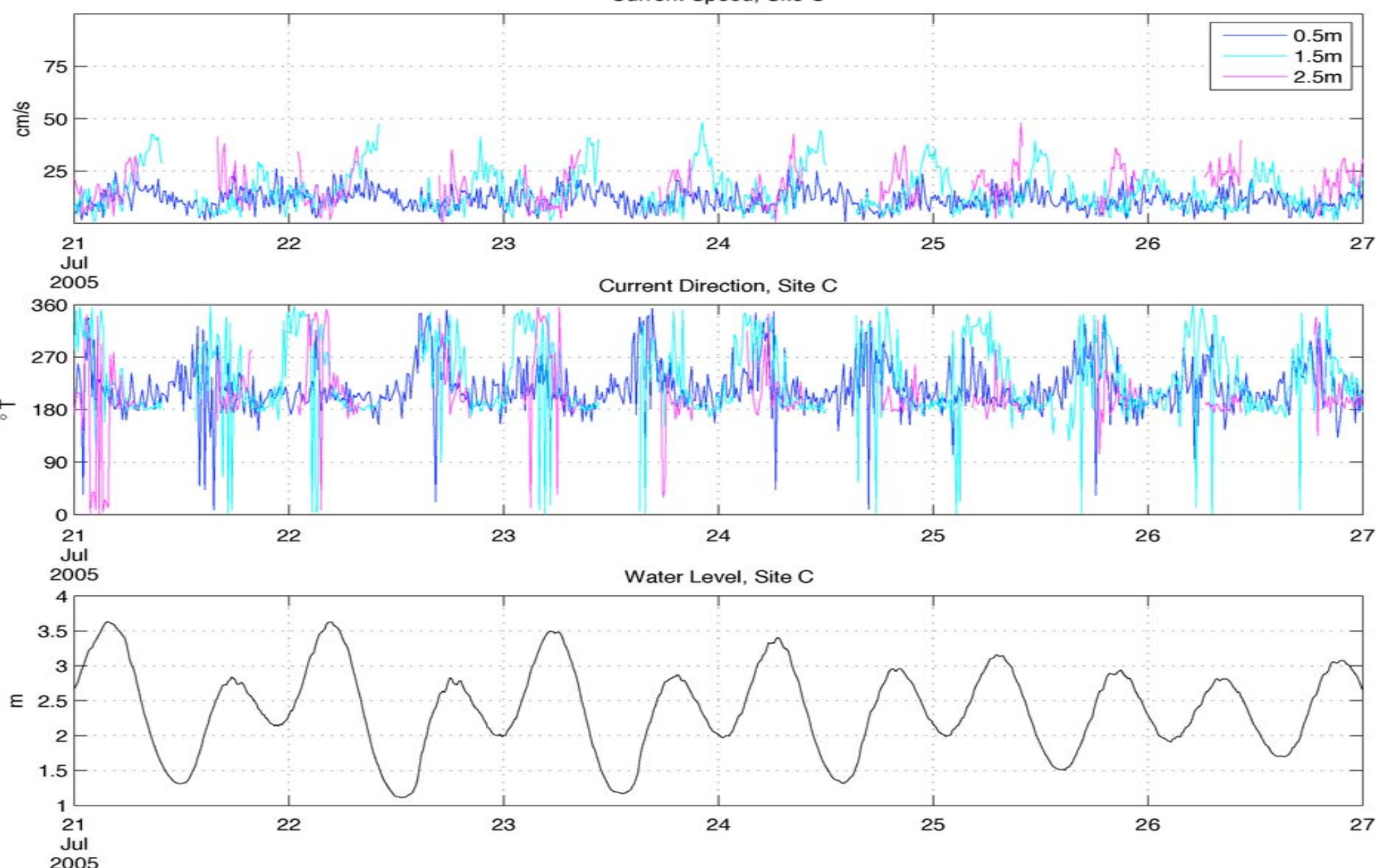

Figure 26. Time series of current speed, direction and water level at several depths (listed as distance above the bed) as recorded by Nortek Aquadopp at Site C, for one week of deployment. 

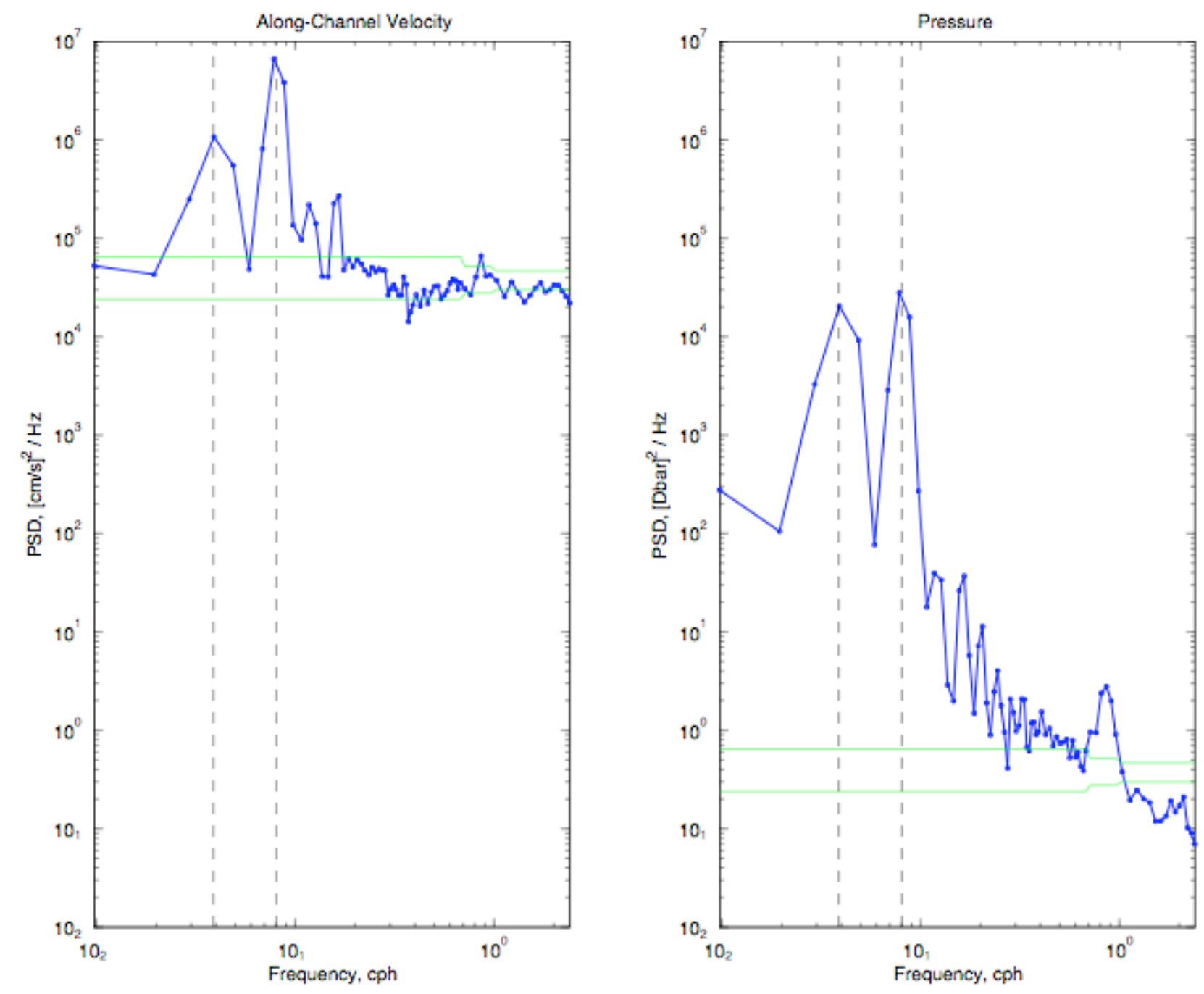

Figure 27. Power spectra of along-channel velocity and water-level data at Site C. 


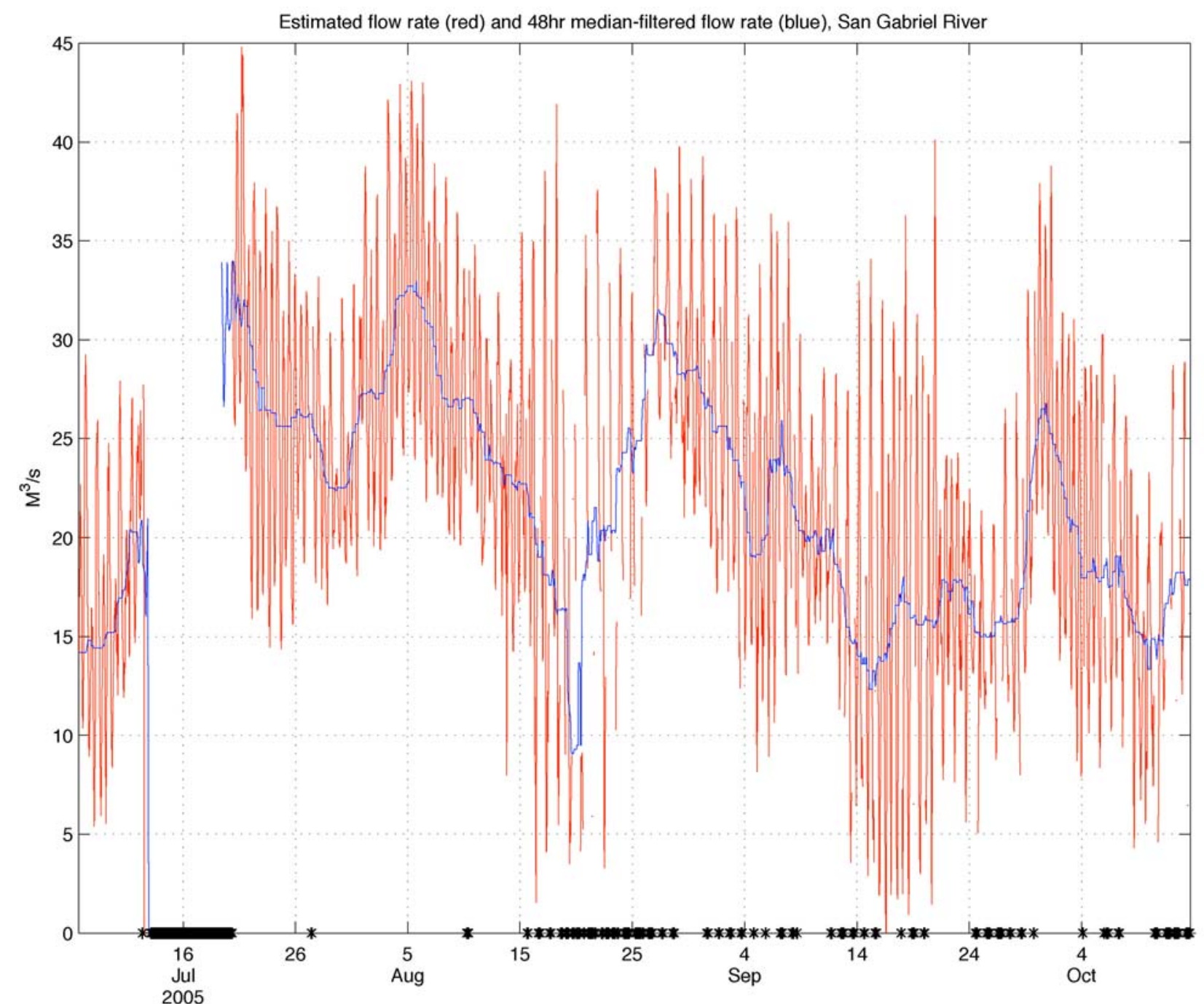

Figure 28. Estimate of flow rate in SGR estuary derived from hourly ADCP measurements at Site B (red) and a 48-hour median filter of the estimated flow rate (blue). Black stars indicate where gaps in data still occur after interpolation. 


\begin{tabular}{|c|c|c|c|c|c|c|c|c|c|c|}
\hline Site & Position & $\begin{array}{c}\text { USGS } \\
\text { Number }\end{array}$ & Instrument & $\begin{array}{c}\text { Parameters } \\
\text { Measured }\end{array}$ & Sampling & $\begin{array}{l}\text { Water } \\
\text { Depth }\end{array}$ & Deployed & Latitude & Longitude & Recovered \\
\hline \multirow{4}{*}{$\mathbf{A}$} & Surface & 801-1 & SBE-37 MicroCat & $\mathrm{T}, \mathrm{S}$ & $60 \mathrm{sec}$ & $10.3 \mathrm{ft}$ & $7 / 6 / 05 \quad 17: 30$ & $33.75125 \mathrm{~N}$ & $118.10735 \mathrm{~W}$ & $9 / 1 / 05$ \\
\hline & & & & & & Moved & & $33.74397 \mathrm{~N}$ & $118.11409 \mathrm{~W}$ & \\
\hline & Surface - 2 & 807-1 & SBE-37 MicroCat & $\mathrm{T}, \mathrm{S}$ & $60 \mathrm{sec}$ & & 9/1/05 23:11 & $33.75117 \mathrm{~N}$ & $118.10747 \mathrm{~W}$ & $10 / 13 / 05$ 15:1 \\
\hline & Bottom & $802-1$ & SBE-37 MicroCat & $\mathrm{T}, \mathrm{S}, \mathrm{P}$ & $60 \mathrm{sec}$ & $10.2 \mathrm{ft}$ & $7 / 6 / 05 \quad 17: 26$ & $33.75135 \mathrm{~N}$ & $118.10721 \mathrm{~W}$ & 10/13/05 17: \\
\hline
\end{tabular}

\begin{tabular}{|c|c|c|c|c|c|c|c|c|c|c|}
\hline \multirow{5}{*}{ B } & Surface & $799-1$ & SBE-37 MicroCat & $\mathrm{T}, \mathrm{S}$ & $60 \mathrm{sec}$ & $10.3 \mathrm{ft}$ & 7/6/05 17:04 & $33.75860 \mathrm{~N}$ & $118.09856 \mathrm{~W}$ & $9 / 1 / 05$ \\
\hline & & & & & & Moved & & $33.75193 \mathrm{~N}$ & $118.10583 \mathrm{~W}$ & \\
\hline & Surface - 2 & 806-1 & SBE-37 MicroCat & $\mathrm{T}, \mathrm{S}$ & $60 \mathrm{sec}$ & & $9 / 1 / 05 \quad 0: 33$ & $33.75842 \mathrm{~N}$ & $118.09863 \mathrm{~W}$ & 10/13/05 16: \\
\hline & Bottom & $800-1$ & $\begin{array}{l}\text { RDI ACDP } 1.2 \\
\mathrm{MHz}\end{array}$ & $\mathrm{U}, \mathrm{V}, \mathrm{W}, \mathrm{T}, \mathrm{P}$ & $\begin{array}{l}120 \text { s, } \\
\text { every } 6 \\
\text { min }\end{array}$ & $10.3 \mathrm{ft}$ & 7/6/05 16:57 & $33.75872 \mathrm{~N}$ & $118.09853 \mathrm{~W}$ & 10/13/05 16: \\
\hline & & $800-2$ & SBE-37 MicroCat & $\mathrm{T}, \mathrm{S}, \mathrm{P}$ & $60 \mathrm{sec}$ & & & & & \\
\hline
\end{tabular}

\begin{tabular}{|c|c|c|c|c|c|c|c|c|c|c|}
\hline \multirow{4}{*}{$\mathbf{C}$} & Surface & $797-1$ & SBE-37 MicroCat & $\mathrm{T}, \mathrm{S}$ & $60 \mathrm{sec}$ & $8 \mathrm{ft}$ & $7 / 6 / 0516: 17$ & $33.772312 \mathrm{~N}$ & $118.09767 \mathrm{~W}$ & 10/13/05 16: \\
\hline & Bottom & 798-1 & $\begin{array}{l}\text { Nortek ADP } 2 \\
\text { MHz }\end{array}$ & $\mathrm{U}, \mathrm{V}, \mathrm{W}, \mathrm{T}, \mathrm{P}$ & $\begin{array}{l}180 \text { s, } \\
\text { every } 12 \\
\text { min }\end{array}$ & $8 \mathrm{ft}$ & 7/6/05 16:01 & $33.77245 \mathrm{~N}$ & $118.09769 \mathrm{~W}$ & 10/13/05 17: \\
\hline & & 798-2 & SBE-37 MicroCat & $\mathrm{T}, \mathrm{S}$ & $60 \mathrm{sec}$ & & & & & \\
\hline & & & & & & & & & & \\
\hline
\end{tabular}

Table 1. List of instruments deployed, parameters measured, and deployment locations and dates. 


\begin{tabular}{|c|c|c|c|c|c|c|}
\hline \multirow{3}{*}{ Site } & $\begin{array}{c}\text { Parameters } \\
\text { Measured }\end{array}$ & Instrument & $\begin{array}{c}\text { Depth Level/ Distance } \\
\text { off Bed }\end{array}$ & $\begin{array}{c}\text { Sampling } \\
\text { Rate }\end{array}$ & $\begin{array}{c}\text { Number of days of } \\
\text { data }\end{array}$ & File Name \\
\hline \multirow{4}{*}{ A } & Temperature & MicroCat & Surface $-1 \mathrm{~m}$ & 1 minute & $56+42$ & $8011 \mathrm{mc} . \mathrm{nc}, 8071 \mathrm{mc} . \mathrm{nc}$ \\
\cline { 2 - 7 } & & MicroCat & Bottom $-10 \mathrm{~cm}$ & 1 minute & 59 & $8021 \mathrm{mc} . \mathrm{nc}$ \\
\cline { 2 - 7 } & Salinity & MicroCat & Surface $-1 \mathrm{~m}$ & 1 minute & $56+42$ & $8011 \mathrm{mc} . \mathrm{nc}, 8071 \mathrm{mc} . \mathrm{nc}$ \\
\cline { 2 - 7 } & & MicroCat & Bottom $-10 \mathrm{~cm}$ & 1 minute & 59 & $8021 \mathrm{mc} . \mathrm{nc}$ \\
\cline { 2 - 7 } & Pressure & MicroCat & Bottom $-10 \mathrm{~cm}$ & 1 minute & 59 & $8021 \mathrm{mc} . \mathrm{nc}$ \\
\hline
\end{tabular}

\begin{tabular}{|c|c|c|c|c|c|c|}
\hline \multirow{8}{*}{ B } & Temperature & MicroCat & Surface - $1 \mathrm{~m}$ & 1 minute & $56+42$ & 7991mc.nc,8061mc.nc \\
\hline & & MicroCat & Bottom $-10 \mathrm{~cm}$ & 1 minute & 85 & $8002 \mathrm{mc} . n \mathrm{c}$ \\
\hline & & RDI ADCP & Bottom $-20 \mathrm{~cm}$ & 6 minute & 100 & 8001wh.nc \\
\hline & Salinity & MicroCat & Surface $-1 \mathrm{~m}$ & 1 minute & $56+42$ & 7991mc.nc,8061mc.nc \\
\hline & & MicroCat & Bottom $-10 \mathrm{~cm}$ & 1 minute & 85 & 8002mc.nc \\
\hline & Currents & RDI ADCP & Water column Profile & 6 minute & Intermittent & 8001wh.nc \\
\hline & Pressure & RDI ADCP & Bottom - $20 \mathrm{~cm}$ & 6 minute & 98 & 8001wh.nc \\
\hline & & MicroCat & Bottom $-10 \mathrm{~cm}$ & 1 minute & 98 & $8002 \mathrm{mc} \cdot \mathrm{nc}$ \\
\hline
\end{tabular}

\begin{tabular}{|c|c|c|c|c|c|c|}
\hline \multirow{4}{*}{} & Temperature & MicroCat & Surface $-1 \mathrm{~m}$ & 1 minute & 98 & $7971 \mathrm{mc} . \mathrm{nc}$ \\
\cline { 2 - 7 } & & MicroCat & Bottom & 1 minute & 58 & $7982 \mathrm{mc} . n \mathrm{c}$ \\
\cline { 2 - 7 } & Salinity & MicroCat & Surface $-1 \mathrm{~m}$ & 1 minute & 98 & $7971 \mathrm{mc} . n \mathrm{c}$ \\
\cline { 2 - 7 } & & MicroCat & Bottom & 1 minute & 58 & $7982 \mathrm{mc} . n \mathrm{c}$ \\
\cline { 2 - 7 } & Currents & Nortek Aquadopp & Water Column Profile & 12 minute & 72 & $7981 \mathrm{aqd} . \mathrm{nc}$ \\
\cline { 2 - 7 } & Pressure & Nortek Aquadopp & Bottom & 12 minute & 72 & $7981 \mathrm{aqd} . \mathrm{nc}$ \\
\cline { 2 - 7 } & Temperature & Nortek Aquadopp & Bottom & 12 minute & 72 & $7981 \mathrm{aqd} . \mathrm{nc}$ \\
\hline
\end{tabular}

Table 2. List of data acquired and data file names. Where two numbers are listed under 'Number of days of data', these refer to the two individual instrument deployments. 